\title{
Supply Chain Bilateral Coordination with Option Contracts under Inflation Scenarios
}

\author{
Nana Wan and Xu Chen \\ School of Management and Economics, University of Electronic Science and Technology of China, Chengdu 611731, China
}

Correspondence should be addressed to Xu Chen; xchenxchen@263.net

Received 28 January 2015; Accepted 21 April 2015

Academic Editor: Chuanxi Qian

Copyright (c) 2015 N. Wan and X. Chen. This is an open access article distributed under the Creative Commons Attribution License, which permits unrestricted use, distribution, and reproduction in any medium, provided the original work is properly cited.

There exist obvious changes in price and demand during the inflationary period, both of which are regarded as the key factors leading to supply chain uncertainty. In this paper, we focus our discussion on price increase and demand contraction caused by inflation, integrate the effect of inflation and option contracts within the model framework, and analyze how to use option contracts to achieve supply chain coordination under inflation scenarios. We consider a one-period two-stage supply chain consisting of one supplier and one retailer and explore the effect of inflation on the optimal ordering and production decisions under three different types of contracts: wholesale price contracts, option contracts, and portfolio contracts. Moreover, we explore the impact of option contracts on the supply chain through using wholesale price contracts model as the benchmark. We find that the retailer prefers adopting portfolio contracts, but the supplier prefers providing option contracts under inflation scenarios. Ultimately, option contracts will be implemented owing to the supplier's market dominant position. In addition, we discuss the supply chain bilateral coordination mechanism with option contracts from the perspectives of two members and derive that option contracts can coordinate the supply chain and achieve Pareto improvement under inflation scenarios.

\section{Introduction}

Along with the continued development of economic globalization, economy in one country is more susceptible to what happens in other countries. Owing to the global financial crisis, inflation has been emerging in recent years. This is true not only in developing countries but also in developed countries. According to the latest reports by Statistics, the global inflation rate from 2004 to 2014 has always deviated far from $2 \%$ inflation target [1], which suggests that inflation has a negative impact on the enterprise operation and poses a threat to the real economics. As we have seen, a lot of issues seem to appear as the inflationary pressure spreading to all aspects of the economy. The most obvious changes that occur during inflation are price and demand, both of which are considered as the significant factors impacting supply chain risk. We can observe that there exists a remarkable increase in price due to the effect of inflation. Over the past few years, food prices have climbed to previously unknown heights and nonfood prices have gone up dramatically around the world. People need to spend more money to buy the same goods and services than they did in the past. Moreover, we can also observe that there exists a remarkable decrease in demand due to the effect of inflation. In recent years, sales of many items such as clothing and cars continue to shrink and a large number of firms are trapped in the survive crisis. The main reason for this feature is because wages fail to keep up with rising price under inflation scenarios, which results in the relative decline of individual incomes and the direct reduction of purchasing powers. Since companies are inseparable from their partners, the effect of inflation can exert great influence on the daily operations of the supply chain. Thus, how to manage these two risks just mentioned becomes the key issue that needs to be addressed urgently in supply chain management applications. So far, the effect of inflation has been studied in inventory management applications, but it has not been addressed in supply chain management applications. Motivated by this, we plan to study how the supply chain members make the optimal decision policies under inflation scenarios.

Options have been demonstrated to be a viable instrument to protect against the effect of inflation in financial applications [2]. We introduce option contracts into supply chain management to hedge the risk of price increase and 
demand contraction caused by inflation. It is worth noting that options in supply chain management applications, different from options in financial applications, are considered as real options. In addition, option contracts are always classified into three categories $[3,4]$ and we limit our discussion to call option contracts in this paper. Option contracts can help the demand-side obtain the goods after the market demand is realized and provide the demand-side with more flexibility to accommodate changing market. Option contracts can also help the supply-side make a production plan that maximizes its own profit and provide the supplyside with more flexibility to reduce the production cost. In the real world, many famous companies such as HP [5], Sun [6], and IBM [7] adapt derivatives of option contracts to purchase various inputs such as memory chips and scanner assemblies. Since then, extensive attentions from scholars are paid to option contracts. So far, there are many papers relating to option contacts under various scenarios in supply chain management applications. However, all these papers do not consider the effect of inflation. Motivated by this, we plan to study whether option contracts are an efficient tool to resolve channel conflicts and achieve channel coordination under inflation scenarios.

On the other hand, the coordination problem has always been an important part in the study on supply chain management. As we know, there exists double marginalization phenomenon under the decentralized decision-making [8]. The primary purpose of channel coordination is to prompt the members involved to carry out the actions which are consistent with the supply chain's objective [9]. To the best of our knowledge, except for some scenarios such as random yield, the supply-side is always assumed to adopt the maketo-order production policy and commit to manufacturing the products up to the order requirement of the demand-side under various contract types such as buyback contracts and revenue sharing contracts. In this case, supply chain coordination can be achieved only when the demand-side decision under the decentralized situation is the same as the integrated decision under the centralized situation. At this moment, how to make a nonintegrated supply chain coordinate is simplified to the supply chain unilateral coordination from the demand-side perspective. However, the supply-side has a strong incentive to decide the production quantity according to the profit maximization rule in the presence of option contracts. The major reason is because option contracts give the right, not the obligation, to obtain the items and so the demand-side may not exercise all the options purchased. Obviously, this poses a challenge on the implementation of supply chain unilateral coordination mechanism in the presence of option contracts. Motivated by this, we design the supply chain bilateral coordination mechanism from the perspective of both the demand-side and the supply-side in the presence of option contracts.

In this paper, we consider one-period two-stage supply chain which contains one supplier and one retailer. Considering price increase and demand contraction due to the effect of inflation, we introduce option contracts into supply chain decision-making in order to hedge against these risks just mentioned. This paper mainly solves the following problems.
(1) What are the optimal ordering and production policies for the supply chain members in the presence of option contracts under inflation scenarios?

(2) What are the optimal expected profits for the supply chain members in the presence of option contracts under inflation scenarios?

(3) What effect does inflation have on the optimal ordering and production policies?

(4) What effect do option contracts have on supply chain under inflation scenarios?

(5) How should option contracts be set to achieve supply chain coordination under inflation scenarios?

The main contributions of our work are as follows.

(1) To the best of our knowledge, there are no published papers that study the use of option contracts to protect against the effect of inflation in supply chain management applications. We develop supply chain models that incorporate the effect of inflation and option contracts in this paper. Our objective is to provide management insights into the effect of inflation and option contracts on the supply chain.

(2) We explore the effect of inflation on the retailer's optimal ordering policy and the supplier's optimal production policy and gain many management interesting results.

(3) We explore the impact of option contracts on the supply chain through using wholesale price contracts model as the benchmark and discuss which kind of contracts is more suitable for supply chain members under inflation scenarios.

(4) We design the bilateral coordination mechanism from the perspective of both the supplier and the retailer and achieve an efficient channel under inflation scenarios.

The remaining part of this paper is structured as follows. A summary of related literature is presented in Section 2. The model formulation and assumptions are given in Section 3. We establish supply chain models with three different contracts and explore the effect of inflation on the optimal decision policies in Section 4. We discuss the impact of option contracts on the supply chain decisions and performance in Section 5. Coordination conditions with option contracts under inflation scenarios are considered in Section 6. We provide a numerical example to illustrate the effect of inflation on the optimal decisions and the optimal expected profits in Section 7. We conclude our findings in Section 8 and highlight possible future work.

\section{Literature Review}

We first review the literature on enterprise operation management under inflation scenarios. Dey et al. [10] solve a deteriorating inventory problem with two warehouses considering time value of money and interval-valued lead time 
under inflation. Jaggi and Khanna [11] formulate an inventory model for deteriorating items with inflation-induced demand when trade credit policy and time discounting with allowable shortages are considered. Yang et al. [12] investigate the optimal replenishment policy with stock-dependent consumption rate under inflation when partial backlogging is considered. Sarkar et al. [13] establish an EMQ model with time-dependent demand and an imperfect production process under inflation and time value of money. Tripathi [14] investigates the optimal pricing and ordering decisions for a deteriorating inventory when demand is a function of price inflation and delay in payment is permissible. Taheri-Tolgari et al. [15] study the production problem for imperfect items where inflation and inspection errors are considered. Mirzazadeh [16] deals with a deteriorating inventory model with inflation-dependent demand and partial backlogging under stochastic inflationary conditions. Guria et al. [17] present an inventory policy considering inflation and selling price-dependent demand under deterministic and stochastic planning horizons. Mousavi et al. [18] use the mixed binary integer mathematical programming approach to resolve multi-item multiperiod inventory control problem considering quantity discounts, interest, and inflation factors. Gilding [19] proposes the optimal inventory replenishment schedule with time-dependent demand and inflation in a finite time horizon. Pal et al. [20] formulate a production inventory model with the effect of inflation under fuzzy environment. These papers are from the viewpoint of inventory management and mainly focus on the optimal replenishment or production strategy for one single enterprise under inflationary conditions. They do not consider the effect of inflation on a supply chain. In addition, they do not also consider option contracts.

We now examine the literature on supply chain management with option contracts. Li et al. [21] investigate the value of forward contracts and option contracts on a supplierretailer system with asymmetric information, in which both members face price and demand uncertainty. Zhao et al. [22] adopt a cooperative game method to study the coordination problem with option contracts. They find that option contracts can coordinate the supply chain to achieve Pareto improvement. Xu [23] obtains the optimal procurement and production decisions in a supplier-manufacturer system under option contracts when the uncertainties such as the supplier's production yield, the instant price, and the market demand are considered. Fu et al. [24] concentrate on a singleperiod portfolio procurement problem and then extend the discussion to a two-period setting when both the demand and the spot price are random. Xia et al. [25] analyze how to share the supply disruption risk and the demand random risk under two different contract mechanisms: wholesale price contracts and option contracts. They find that the benefit of reliable supplier depends on the type of contracts and the buyer prefers the reliable supplier under option contracts. Chen and Shen [26] describe that portfolio contracts bring more benefit for the supply chain members than wholesale price contracts in the presence of a service requirement. They also consider the conditions for the channel coordination with a service requirement. Liang et al. [27] analyze the value of option contracts on the relief material supply chain and find that option contract mechanism can help reduce the impact of disaster and maintain social stability. Lee et al. [28] study the multiple-supplier procurement problem with capacity constraints and fixed ordering costs, when option contracts and spot market are simultaneously used by the buyer. Liu et al. [29] introduce option contracts into container planning mechanism and analyze the application strategies of unilateral and bidirectional option contracts in different practical scenarios. Chen et al. [30] investigate how to apply option contracts to coordinate a channel which contains one supplier and one loss-averse retailer. Hu et al. [31] establish the decision-making model in a manufacturer-retailer system with option contracts and partial backordering when both the production yield and the market demand are stochastic. These papers do not discuss the effect of inflation on a supply chain.

We eventually review the literature on supply chain coordination with contracts. Several contracts such as revenue sharing contracts and buyback contracts are proved to be an efficient approach to coordinate the supply chain under different scenarios. Linh and Hong [32] study how to coordinate a supply chain through revenue sharing contracts in the twoperiod setting. Xiao et al. $[33,34]$ design a mechanism to coordinate a manufacturer-retailer system through buyback contracts and investigate the effects of the consumer return on the coordination strategy. Chiu et al. [35] describe how the policy which contains wholesale price, channel rebate, and returns can achieve the supply chain coordination with both additive and multiplicative price-dependent demands. A comprehensive analysis on supply chain coordination with contracts can be found in Cachon [36]. In these papers, the discussion on the seller's production decision is neglected and only the buyer's order quantity needs coordination. However, the seller can plan the production schedule that maximizes its own profit in the presence of option contracts. To the best of our knowledge, only two papers $[26,30]$ discuss how to coordinate both the buyer's ordering quantity and the seller's production quantity. All the other papers considering option contracts assume that the seller adopts the make-toorder production policy. However, these two papers above do not consider both option contracts and portfolio contracts simultaneously. In addition, all the papers do not discuss the effect of inflation on the supply chain.

\section{Model Formulation and Assumptions}

We consider a one-period two-stage supply chain, in which one supplier manufactures one type of seasonal products, and one retailer purchases from the upstream supplier and sells to the downstream consumers. The retailer obtains the products through three different contracts, respectively: wholesale price contracts, option contracts, and portfolio contracts consisting of wholesale price contracts and option contracts. Under wholesale price contracts, the retailer places a firm order, denoted as $Q_{r 0}$, at unit wholesale price $w$ before the selling period. Then, the supplier receives the firm order and manufactures the products up to $Q_{s 0}$ at unit production cost $c$. When the selling period starts, the retailer obtains 
the products through the firm order. Under option contracts, the retailer only purchases call options, denoted as $q_{r 1}$, at unit purchase price $c_{o}$ before the selling period. Then, the supplier receives the options order and manufactures the products up to $Q_{s 1}$. During the selling period, the retailer observes the realized market demand and then determines how much products to obtain through the options order at unit exercise price $c_{e}$. Under portfolio contracts, the retailer places a firm order, denoted as $Q_{r 2}$, and purchases call options, denoted as $q_{r 2}$. Then, the supplier receives the orders of the two different types and manufactures the products up to $Q_{s 2}$. When the selling period starts, the retailer obtains the products through the firm order. During the selling period, the retailer obtains the additional products through the options order. The retailer incurs a unit shortage cost $g_{r}$ for each unsatisfied demand. The supplier incurs a unit penalty cost $g_{s}$ for each exercised option that cannot be immediately filled. Thus, the supplier's unit penalty cost $g_{s}$ represents the cost to obtain an additional unit of product by expediting production or buying from an alternative source.

In the seasonal product industry, the length of selling period is short but the length of production lead time is long [37]. During the production lead time, both the retail price and the market demand vary with time owing to the effect of inflation. In reality, sometimes the production lead time is considered to be exogenous [33,34]. The empirical studies $[38,39]$ show that the length of production lead time is uncertain. We assume that the length of production lead time, denoted as $t$, is an exogenous random variable over $(0, T)$ with probability density function (PDF) $g(\cdot)$. Similar to Jaggi and Khanna [11], we assume that unit retail price, denoted as $p(t)$, follows a continuous exponential growth during the production lead time under inflation scenarios; that is, $p(t)=p e^{\gamma t}$, where $p$ is the initial retail price and $\gamma(\gamma>0)$ is the price rising factor. Similar to Xiao et al. $[33,34]$, we assume that the market demand, denoted as $D(t)$, is decomposed into a deterministic form $d(t)$ and a nondeterministic error $\xi$; that is, $D(t)=d(t)+\xi$, where $d(t)$ is a decreasing function of the production lead time owing to the effect of inflation and $\xi$ is a random variable over $(0,+\infty)$ with probability density function (PDF) $f(\cdot)$ and strictly increasing cumulative distribution function (CDF) $F(\cdot) . F(0)=0, E(\xi)=\mu$, and $\bar{F}(\cdot)=1-F(\cdot)$ denote the tail distribution. As we know, various time-varying functions can be used to describe $d(t)$ such as linear, Weibull, and exponential distribution forms. Similar to Tripathi [14], an exponentially decreasing pattern is used to describe the market contraction caused by the effect of inflation for the purpose of making the model analytically tractable; that is, $d(t)=\lambda e^{-\alpha t}$, where $\lambda$ is the initial market scale and $\alpha(\alpha>0)$ is the demand contraction factor.

Throughout this paper, we use the parameters and variables as shown in "Notations."

We assume that the supply chain members are rational and self-interested and all the information available is symmetric between the supplier and the retailer. Moreover, we assume that the retailer's initial inventory is zero and any excess product either owned by the retailer or by the supplier can be ignored. Furthermore, we assume that $p e^{\gamma t}>c_{o}+c_{e}>$ $w>c$ and $c_{o}+c_{e}>w>c_{o}$. The first condition can ensure profits for two parties. The second condition can ensure that the retailer places a firm order and purchases call options simultaneously.

\section{Supply Chain Models}

In this section, we plan to study the retailer's optimal ordering policy and the supplier's optimal production policy considering the effect of inflation under three different types of contracting arrangement: wholesale price contracts, option contracts, and portfolio contracts.

\subsection{Wholesale Price Contracts Model}

4.1.1. Optimal Ordering Policy under Wholesale Price Contracts. Since wholesale price contracts are widely used in practice, we use wholesale price contracts model as the benchmark and compare with option contracts model and portfolio contracts model developed in the remaining part.

Under wholesale price contracts, only products are purchased from the upstream supplier and the expected profit of the retailer, denoted as $\Pi_{r 0}\left(Q_{r 0}\right)$, is given by

$$
\begin{aligned}
& \Pi_{r 0}\left(Q_{r 0}\right)=\int_{0}^{T}\left\{p(t) \min \left[D(t), Q_{r 0}\right]-w Q_{r 0}\right. \\
& \left.-g_{r}\left[D(t)-Q_{r 0}\right]^{+}\right\} g(t) d t .
\end{aligned}
$$

The first term is the sales revenue. The second term is the costs of purchasing products, and the last term is the shortage cost. Then, the above equation can be simplified as

$$
\begin{aligned}
\Pi_{r 0}\left(Q_{r 0}\right) & \\
= & Q_{r 0} \int_{0}^{T}\left(p e^{\gamma t}+g_{r}-w\right) g(t) d t \\
& \quad-g_{r} \int_{0}^{T} \lambda e^{-\alpha t} g(t) d t-g_{r} \mu \\
& \quad-\int_{0}^{T} \int_{0}^{Q_{r 0}-\lambda e^{-\alpha t}}\left(p e^{\gamma t}+g_{r}\right) F(x) g(t) d x d t .
\end{aligned}
$$

As to the retailer's optimal ordering policy under wholesale price contracts, we can derive the following proposition.

Proposition 1. Under wholesale price contracts, the retailer's optimal firm order quantity $Q_{r 0}^{*}$ is

$$
\int_{0}^{T}\left(p e^{\gamma t}+g_{r}\right) \bar{F}\left(Q_{r 0}^{*}-\lambda e^{-\alpha t}\right) g(t) d t=w .
$$

Proof. From (2), we can derive that $d \Pi_{r 0}\left(Q_{r 0}\right) / d Q_{r 0}=$ $\int_{0}^{T}\left(p e^{\gamma t}+g_{r}-w\right) g(t) d t-\int_{0}^{T}\left(p e^{\gamma t}+g_{r}\right) F\left(Q_{r 0}-\lambda e^{-\alpha t}\right) g(t) d t$ and $d^{2} \Pi_{r 0}\left(Q_{r 0}\right) / d Q_{r 0}^{2}=-\int_{0}^{T}\left(p e^{\gamma t}+g_{r}\right) f\left(Q_{r 0}-\lambda e^{-\alpha t}\right) g(t) d t<0$, so $\Pi_{r 0}\left(Q_{r 0}\right)$ is concave in $Q_{r 0}$. Let $d \Pi_{r 0}\left(Q_{r 0}\right) / d Q_{r 0}=0$; we can obtain that the optimal solution to (2) is $\int_{0}^{T}\left(p e^{\gamma t}+\right.$ $\left.g_{r}\right) \bar{F}\left(Q_{r 0}^{*}-\lambda e^{-\alpha t}\right) g(t) d t=w$. 
This proposition shows that the effect of inflation has a significant impact on the retailer's optimal ordering policy under wholesale price contracts. We have the following corollary.

Corollary 2. The retailer's optimal firm order quantity under wholesale price contracts is decreasing in $\alpha$ and increasing in $\gamma$.

Proof. Let $L_{0}\left(Q_{r 0}^{*}\right)=\int_{0}^{T}\left(p e^{\gamma t}+g_{r}\right) \bar{F}\left(Q_{r 0}^{*}-\right.$ $\left.\lambda e^{-\alpha t}\right) g(t) d t-w$; we can derive that $\partial Q_{r 0}^{*} / \partial \alpha=$ $-\left(\partial L_{0}\left(Q_{r 0}^{*}\right) / \partial \alpha\right) /\left(\partial L_{0}\left(Q_{r 0}^{*}\right) / \partial Q_{r 0}^{*}\right)=-\int_{0}^{T} \lambda t e^{-\alpha t}\left(p e^{\gamma t}+\right.$ $\left.g_{r}\right) f\left(Q_{r 0}^{*}-\lambda e^{-\alpha t}\right) g(t) d t / \int_{0}^{T}\left(p e^{\gamma t}+g_{r}\right) f\left(Q_{r 0}^{*}-\lambda e^{-\alpha t}\right) g(t) d t<$ 0 and $\partial Q_{r 0}^{*} / \partial \gamma=-\left(\partial L_{0}\left(Q_{r 0}^{*}\right) / \partial \gamma\right) /\left(\partial L_{0}\left(Q_{r 0}^{*}\right) / \partial Q_{r 0}^{*}\right)=$ $\int_{0}^{T} p t e^{\gamma t} \bar{F}\left(Q_{r 0}^{*}-\lambda e^{-\alpha t}\right) g(t) d t / \int_{0}^{T}\left(p e^{\gamma t}+g_{r}\right) f\left(Q_{r 0}^{*}-\right.$ $\left.\lambda e^{-\alpha t}\right) g(t) d t>0$; that is, the retailer's optimal firm order quantity under wholesale price contracts is decreasing in $\alpha$ and increasing in $\gamma$.

From Corollary 2, we can see that when the demand contraction factor $\alpha$ grows, the retailer will reduce the size of the firm order. When the price rising factor $\gamma$ grows, the retailer will enlarge the size of the firm order. Since both price and demand vary in two opposite directions due to the effect of inflation, this poses a challenge for the retailer to decide whether to increase or decrease the size of the firm order. At this moment, the retailer needs to seek the right balance between the rising price and the shrinking demand. When the increase in the retail price is more obvious, the retailer will increase the firm order quantity. When the decrease in the market demand is more obvious, the retailer will decrease the firm order quantity.

4.1.2. Optimal Production Policy under Wholesale Price Contracts. Since the retailer obtains the products through the firm order at the beginning of the selling period, the supplier's optimal production quantity is equivalent to the retailer's optimal firm order quantity under wholesale price contracts. That is, $Q_{s 0}^{*}=Q_{r 0}^{*}$. Obviously, the supplier's optimal production quantity under wholesale price contracts is also decreasing in $\alpha$ and increasing in $\gamma$.

Under wholesale price contracts, the optimal expected profit of the supplier, denoted as $\Pi_{s 0}\left(Q_{s 0}^{*}\right)$, is given by

$$
\Pi_{s 0}\left(Q_{s 0}^{*}\right)=(w-c) Q_{s 0}^{*}=(w-c) Q_{r 0}^{*} .
$$

\subsection{Option Contracts Model}

4.2.1. Optimal Ordering Policy under Option Contracts. Under option contracts, only call options are purchased from the upstream supplier and the expected profit of the retailer, denoted as $\Pi_{r 1}\left(q_{r 1}\right)$, is given by

$$
\begin{aligned}
& \Pi_{r 1}\left(q_{r 1}\right)=\int_{0}^{T}\left\{p(t) \min \left[D(t), q_{r 1}\right]-c_{o} q_{r 1}\right. \\
& \left.-c_{e} \min \left[D(t), q_{r 1}\right]-g_{r}\left[D(t)-q_{r 1}\right]^{+}\right\} g(t) d t .
\end{aligned}
$$

The first term is the sales revenue. The second term is the costs of purchasing call options. The third term is the costs of exercising call options, and the last term is the shortage cost. Then, the above equation can be simplified as

$$
\begin{aligned}
& \Pi_{r 1}\left(q_{r 1}\right) \\
& =q_{r 1} \int_{0}^{T}\left(p e^{\gamma t}+g_{r}-c_{o}-c_{e}\right) g(t) d t \\
& \quad-g_{r} \int_{0}^{T} \lambda e^{-\alpha t} g(t) d t-g_{r} \mu \\
& \quad-\int_{0}^{T} \int_{0}^{q_{r 1}-\lambda e^{-\alpha t}}\left(p e^{\gamma t}+g_{r}-c_{e}\right) F(x) g(t) d x d t
\end{aligned}
$$

As to the retailer's optimal ordering policy under option contracts, we can derive the following proposition.

Proposition 3. Under option contracts, the retailer's optimal options order quantity $q_{r 1}^{*}$ is

$$
\int_{0}^{T}\left(p e^{\gamma t}+g_{r}-c_{e}\right) \bar{F}\left(q_{r 1}^{*}-\lambda e^{-\alpha t}\right) g(t) d t=c_{o} .
$$

Proof. From (6), we can derive that $d \Pi_{r 1}\left(q_{r 1}\right) / d q_{r 1}=$ $\int_{0}^{T}\left(p e^{\gamma t}+g_{r}-c_{o}-c_{e}\right) g(t) d t-\int_{0}^{T}\left(p e^{\gamma t}+g_{r}-c_{e}\right) F\left(q_{r 1}-\right.$ $\left.\lambda e^{-\alpha t}\right) g(t) d t$ and $d^{2} \Pi_{r 1}\left(q_{r 1}\right) / d q_{r 1}^{2}=-\int_{0}^{T}\left(p e^{\gamma t}+g_{r}-\right.$ $\left.c_{e}\right) f\left(q_{r 1}-\lambda e^{-\alpha t}\right) g(t) d t<0$, so $\Pi_{r 1}\left(q_{r 1}\right)$ is concave in $q_{r 1}$. Let $d \Pi_{r 1}\left(q_{r 1}\right) / d q_{r 1}=0$; we can obtain that the optimal solution to (6) is $\int_{0}^{T}\left(p e^{\gamma t}+g_{r}-c_{e}\right) \bar{F}\left(q_{r 1}^{*}-\lambda e^{-\alpha t}\right) g(t) d t=c_{o}$.

This proposition shows that the effect of inflation has a significant impact on the retailer's optimal ordering policy under option contracts. We have the following corollary.

Corollary 4. The retailer's optimal options order quantity under option contracts is decreasing in $\alpha$ and increasing in $\gamma$.

Proof. Let $L_{1}\left(q_{r 1}^{*}\right)=\int_{0}^{T}\left(p e^{\gamma t}+g_{r}-c_{e}\right) \bar{F}\left(q_{r 1}^{*}-\lambda e^{-\alpha t}\right) g(t) d t-c_{o}$; we can derive that $\partial q_{r 1}^{*} / \partial \alpha=-\left(\partial L_{1}\left(q_{r 1}^{*}\right) / \partial \alpha\right) /\left(\partial L_{1}\left(q_{r 1}^{*}\right) / \partial q_{r 1}^{*}\right)=$ $-\int_{0}^{T} \lambda t e^{-\alpha t}\left(p e^{\gamma t}+g_{r}-c_{e}\right) f\left(q_{r 1}^{*}-\lambda e^{-\alpha t}\right) g(t) d t / \int_{0}^{T}\left(p e^{\gamma t}+\right.$ $\left.g_{r}-c_{e}\right) f\left(q_{r 1}^{*}-\lambda e^{-\alpha t}\right) g(t) d t<0$ and $\partial q_{r 1}^{*} / \partial \gamma=-\left(\partial L_{1}\left(q_{r 1}^{*}\right) /\right.$ $\partial \gamma) /\left(\partial L_{1}\left(q_{r 1}^{*}\right) / \partial q_{r 1}^{*}\right)=\int_{0}^{T} p t e^{\gamma t} \bar{F}\left(q_{r 1}^{*}-\lambda e^{-\alpha t}\right) g(t) d t /$ $\int_{0}^{T}\left(p e^{\gamma t}+g_{r}-c_{e}\right) f\left(q_{r 1}^{*}-\lambda e^{-\alpha t}\right) g(t) d t>0$; that is, the retailer's optimal options order quantity under option contracts is decreasing in $\alpha$ and increasing in $\gamma$.

From Corollary 4, we can see that when more call options are purchased, the retailer has a higher ability to be resistant to the price rising and a lower ability to be resistant to the demand contraction. When fewer call options are purchased, the retailer has a lower ability to be resistant to the price rising and a higher ability to be resistant to the demand contraction. Owing to the effect of inflation, the retailer must make careful observations on the changes in price and demand and then decide whether to increase or decrease the options order. When the increase in the retail price is more 
obvious, the retailer will order more call options. When the decrease in the market demand is more obvious, the retailer will order fewer call options.

4.2.2. Optimal Production Policy under Option Contracts. Since the retailer obtains the products through the options order during the selling period and the retailer may not exercise all the options purchased, the supplier's optimal production quantity cannot exceed the retailer's optimal options order quantity under option contracts. That is, $Q_{s 1} \leq$ $q_{r 1}^{*}$.

Under option contracts, the optimal expected profit of the supplier, denoted as $\Pi_{s 1}\left(Q_{s 1}\right)$, is given by

$$
\begin{aligned}
& \Pi_{s 1}\left(Q_{s 1}\right)=\int_{0}^{T}\left\{c_{o} q_{r 1}^{*}+c_{e} \min \left[D(t), q_{r 1}^{*}\right]\right. \\
& \left.\quad-g_{s}\left[\min \left(D(t), q_{r 1}^{*}\right)-Q_{s 1}\right]^{+}-c Q_{s 1}\right\} g(t) d t .
\end{aligned}
$$

The first term is the revenue realized from options sales. The second term is the revenue realized from exercised options. The third term is the penalty cost, and the last term is the production cost. Then, the above equation can be simplified as

$$
\begin{aligned}
\Pi_{s 1}\left(Q_{s 1}\right)= & \left(c_{o}+c_{e}-g_{s}\right) q_{r 1}^{*} \\
& +\left(g_{s}-c_{e}\right) \int_{0}^{T} \int_{0}^{q_{r 1}^{*}-\lambda e^{-\alpha t}} F(x) g(t) d x d t \\
& +\left(g_{s}-c\right) Q_{s 1} \\
& -g_{s} \int_{0}^{T} \int_{0}^{Q_{s 1}-\lambda e^{-\alpha t}} F(x) g(t) d x d t .
\end{aligned}
$$

The supplier's decision problem under option contracts is described as

$$
\begin{array}{cl}
\max _{Q_{s 1}>0} & \Pi_{s 1}\left(Q_{s 1}\right) \\
\text { s.t. } & Q_{s 1} \leq q_{r 1}^{*} .
\end{array}
$$

As to the supplier's optimal production policy under option contracts, we can derive the following proposition.

Proposition 5. Under option contracts, the supplier's optimal production quantity $Q_{s 1}^{*}$ satisfies

$$
Q_{s 1}^{*}= \begin{cases}Q_{s 1}^{\varphi} & Q_{s 1}^{\varphi}<q_{r 1}^{*} \\ q_{r 1}^{*} & Q_{s 1}^{\varphi} \geq q_{r 1}^{*},\end{cases}
$$

where $\int_{0}^{T} F\left(Q_{s 1}^{\varphi}-\lambda e^{-\alpha t}\right) g(t) d t=\left(g_{s}-c\right) / g_{s}$.

Proof. From (9), we can derive that $d \Pi_{s 1}\left(Q_{s 1}\right) / d Q_{s 1}=\left(g_{s}-\right.$ c) $-g_{s} \int_{0}^{T} F\left(Q_{s 1}-\lambda e^{-\alpha t}\right) g(t) d t$ and $d^{2} \Pi_{s 1}\left(Q_{s 1}\right) / d Q_{s 1}^{2}=$ $-g_{s} \int_{0}^{T} f\left(Q_{s 1}-\lambda e^{-\alpha t}\right) g(t) d t<0$, so $\Pi_{s 1}\left(Q_{s 1}\right)$ is concave in $Q_{s 1}$. Let $d \Pi_{s 1}\left(Q_{s 1}\right) / d Q_{s 1}=0$; we can derive that the optimal solution to (9) is $\int_{0}^{T} F\left(Q_{s 1}^{\varphi}-\lambda e^{-\alpha t}\right) g(t) d t=\left(g_{s}-c\right) /$ $g_{s}$.
Considering the constraint in (10), the supplier's optimal production quantity under option contracts satisfies

$$
Q_{s 1}^{*}= \begin{cases}Q_{s 1}^{\varphi} & Q_{s 1}^{\varphi}<q_{r 1}^{*} \\ q_{r 1}^{*} & Q_{s 1}^{\varphi} \geq q_{r 1}^{*} .\end{cases}
$$

This proposition shows that, owing to the production constraint condition, the supplier's optimal production quantity under option contracts is expressed as an interval. If $Q_{s 1}^{\varphi}<q_{r 1}^{*}$, the production constraint condition is ineffective. If $Q_{s 1}^{\varphi} \geq q_{r 1}^{*}$, the production constraint condition is effective. At this point, the supplier will try the best to raise the production quantity so as to improve the expected profit. Obviously, the production quantity equivalent to the options order quantity is the supplier's best choice. Moreover, this proposition also shows that the effect of inflation also has a significant impact on the supplier's optimal production policy under option contracts. We have the following corollary.

Corollary 6. The supplier's optimal production quantity under option contracts is decreasing in $\alpha$ and nondecreasing in $\gamma$.

Proof. Let $H_{1}\left(Q_{s 1}^{\varphi}\right)=\left(g_{s}-c\right)-g_{s} \int_{0}^{T} F\left(Q_{s 1}^{\varphi}-\right.$ $\left.\lambda e^{-\alpha t}\right) g(t) d t$. From Proposition 5, we see that if $Q_{s 1}^{\varphi}<q_{r 1}^{*}$, then $Q_{s 1}^{*}=Q_{s 1}^{\varphi}$. We can deduce that $\partial Q_{s 1}^{\varphi} / \partial \alpha=-\left(\partial H_{1}\left(Q_{s 1}^{\varphi}\right) / \partial \alpha\right) /\left(\partial H_{1}\left(Q_{s 1}^{\varphi}\right) / \partial Q_{s 1}^{\varphi}\right)=$ $-\int_{0}^{T} \lambda t e^{-\alpha t} f\left(Q_{s 1}^{\varphi}-\lambda e^{-\alpha t}\right) g(t) d t / \int_{0}^{T} f\left(Q_{s 1}^{\varphi}-\lambda e^{-\alpha t}\right) g(t) d t<0$ and $\partial Q_{s 1}^{\varphi} / \partial \gamma=-\left(\partial H_{1}\left(Q_{s 1}^{\varphi}\right) / \partial \gamma\right) /\left(\partial H_{1}\left(Q_{s 1}^{\varphi}\right) / \partial Q_{s 1}^{\varphi}\right)=0$, so in this case the supplier's optimal production quantity is decreasing in $\alpha$ and constant in $\gamma$. If $Q_{s 1}^{\varphi} \geq q_{r 1}^{*}$, then $Q_{s 1}^{*}=q_{r 1}^{*}$. The supplier's optimal production quantity is decreasing in $\alpha$ and increasing in $\gamma$. Hence, the supplier's optimal production quantity under option contracts is decreasing in $\alpha$ and nondecreasing in $\gamma$.

From Corollary 6, we can see that when the increase in the retail price is more obvious, the supplier will observe the operation status carefully and then decide whether to increase or maintain the production quantity. When the decrease in the market demand is more obvious, the supplier will reduce the production quantity.

\subsection{Portfolio Contracts Model}

4.3.1. Optimal Ordering Policy under Portfolio Contracts. Under portfolio contracts, both products and call options are purchased from the upstream supplier and the expected profit of the retailer, denoted as $\Pi_{r 2}\left(Q_{r 2}, q_{r 2}\right)$, is given by

$$
\begin{aligned}
& \Pi_{r 2}\left(Q_{r 2}, q_{r 2}\right)=\int_{0}^{T}\left\{p(t) \min \left[D(t), Q_{r 2}+q_{r 2}\right]\right. \\
& -w Q_{r 2}-c_{o} q_{r 2}-c_{e} \min \left[\left(D(t)-Q_{r 2}\right)^{+}, q_{r 2}\right] \\
& \left.-g_{r}\left[D(t)-\left(Q_{r 2}+q_{r 2}\right)\right]^{+}\right\} g(t) d t .
\end{aligned}
$$


The first term is the sales revenue. The second term is the costs of purchasing products. The third term is the costs of purchasing call options. The fourth term is the costs of exercising call options, and the last term is the shortage cost. Set $Q_{2}=Q_{r 2}+q_{r 2}$. Note that determining $\left(Q_{r 2}, q_{r 2}\right)$ is equivalent to determining $\left(Q_{r 2}, Q_{2}\right)$. Then, the above function can be rewritten as

$$
\begin{aligned}
\Pi_{r 2}( & \left.Q_{r 2}, Q_{2}\right) \\
= & \left(c_{o}+c_{e}-w\right) Q_{r 2} \\
& -c_{e} \int_{0}^{T} \int_{0}^{Q_{r 2}-\lambda e^{-\alpha t}} F(x) g(t) d x d t \\
& +Q_{2} \int_{0}^{T}\left(p e^{\gamma t}+g_{r}-c_{o}-c_{e}\right) g(t) d t \\
& -g_{r} \int_{0}^{T} \lambda e^{-\alpha t} g(t) d t-g_{r} \mu \\
& -\int_{0}^{T} \int_{0}^{Q_{2}-\lambda e^{-\alpha t}}\left(p e^{\gamma t}+g_{r}-c_{e}\right) F(x) g(t) d x d t .
\end{aligned}
$$

As to the retailer's optimal ordering policy under portfolio contracts, we can derive the following proposition.

Proposition 7. Under portfolio contracts, the retailer's optimal firm order quantity $Q_{r 2}^{*}$ is

$$
\int_{0}^{T} F\left(Q_{r 2}^{*}-\lambda e^{-\alpha t}\right) g(t) d t=\frac{c_{o}+c_{e}-w}{c_{e}} .
$$

The retailer's optimal total order quantity $Q_{2}^{*}$ is

$$
\int_{0}^{T}\left(p e^{\gamma t}+g_{r}-c_{e}\right) \bar{F}\left(Q_{2}^{*}-\lambda e^{-\alpha t}\right) g(t) d t=c_{o} .
$$

Proof. From (14), we can derive that $\partial \Pi_{r 2}\left(Q_{r 2}, Q_{2}\right) / \partial Q_{r 2}=$ $\left(c_{o}+c_{e}-w\right)-c_{e} \int_{0}^{T} F\left(Q_{r 2}-\lambda e^{-\alpha t}\right) g(t) d t, \partial^{2} \Pi_{r 2}\left(Q_{r 2}, Q_{2}\right) / \partial Q_{r 2}^{2}=$ $-c_{e} \int_{0}^{T} f\left(Q_{r 2}-\lambda e^{-\alpha t}\right) g(t) d t<0, \partial \Pi_{r 2}\left(Q_{r 2}, Q_{2}\right) / \partial Q_{2}=$ $\int_{0}^{T}\left(p e^{\gamma t}+g_{r}-c_{o}-c_{e}\right) g(t) d t-\int_{0}^{T}\left(p e^{\gamma t}+g_{r}-c_{e}\right) F\left(Q_{2}-\right.$ $\left.\lambda e^{-\alpha t}\right) g(t) d t, \partial^{2} \Pi_{r 2}\left(Q_{r 2}, Q_{2}\right) / \partial Q_{2}^{2}=-\int_{0}^{T}\left(p e^{\gamma t}+g_{r}-\right.$ $\left.c_{e}\right) f\left(Q_{2}-\lambda e^{-\alpha t}\right) g(t) d t<0$, and $\partial^{2} \Pi_{r 2}\left(Q_{r 2}, Q_{2}\right) / \partial Q_{r 2} \partial Q_{2}=$ $\partial^{2} \Pi_{r 2}\left(Q_{r 2}, Q_{2}\right) / \partial Q_{2} \partial Q_{r 2}=0$. Hence

$$
\left|\begin{array}{ll}
\frac{\partial^{2} \Pi_{r 2}\left(Q_{r 2}, Q_{2}\right)}{\partial Q_{r 2}^{2}} & \frac{\partial^{2} \Pi_{r 2}\left(Q_{r 2}, Q_{2}\right)}{\partial Q_{r 2} \partial Q_{2}} \\
\frac{\partial^{2} \Pi_{r 2}\left(Q_{r 2}, Q_{2}\right)}{\partial Q_{2} \partial Q_{r 2}} & \frac{\partial^{2} \Pi_{r 2}\left(Q_{r 2}, Q_{2}\right)}{\partial Q_{2}^{2}}
\end{array}\right|>0 .
$$

So $\Pi_{r 2}\left(Q_{r 2}, Q_{2}\right)$ is concave in $Q_{r 2}$ and $Q_{2}$. Let $\partial \Pi_{r 2}\left(Q_{r 2}\right.$, $\left.Q_{2}\right) / \partial Q_{r 2}=0$ and $\partial \Pi_{r 2}\left(Q_{r 2}, Q_{2}\right) / \partial Q_{2}=0$; we can obtain that the optimal solution to (14) is $\int_{0}^{T} F\left(Q_{r 2}^{*}-\lambda e^{-\alpha t}\right) g(t) d t=\left(c_{o}+\right.$ $\left.c_{e}-w\right) / c_{e}$ and $\int_{0}^{T}\left(p e^{\gamma t}+g_{r}-c_{e}\right) \bar{F}\left(Q_{2}^{*}-\lambda e^{-\alpha t}\right) g(t) d t=c_{o}$.

From Proposition 7, we can deduce that the retailer's optimal options order quantity is described as $q_{r 2}^{*}=Q_{2}^{*}-Q_{r 2}^{*}$, which implies that the optimal total order quantity is always higher than the optimal firm order quantity under portfolio contracts. Note that $Q_{2}^{*}>Q_{r 2}^{*}$ is equivalent to $c_{o}<\left(\left(p e^{\gamma t}+\right.\right.$ $\left.\left.g_{r}-c_{e}\right) /\left(p e^{\gamma t}+g_{r}\right)\right) w$. This inequality shows that if the supplier charges an exorbitant option price, the retailer will refuse to order any options. Moreover, this proposition shows that the effect of inflation has a significant impact on the retailer's optimal ordering policy under portfolio contracts. We have the following corollary.

Corollary 8. The retailer's optimal firm order quantity under portfolio contracts is decreasing in $\alpha$ and constant in $\gamma$.

Proof. Let $L_{2}\left(Q_{r 2}^{*}\right)=\left(c_{o}+c_{e}-w\right)-c_{e} \int_{0}^{T} F\left(Q_{r 2}^{*}-\right.$ $\left.\lambda e^{-\alpha t}\right) g(t) d t$; we can derive that $\partial Q_{r 2}^{*} / \partial \alpha=$ $-\left(\partial L_{2}\left(Q_{r 2}^{*}\right) / \partial \alpha\right) /\left(\partial L_{2}\left(Q_{r 2}^{*}\right) / \partial Q_{r 2}^{*}\right)=-\int_{0}^{T} \lambda t e^{-\alpha t} f\left(Q_{r 2}^{*}-\right.$ $\left.\lambda e^{-\alpha t}\right) g(t) d t / \int_{0}^{T} f\left(Q_{r 2}^{*}-\lambda e^{-\alpha t}\right) g(t) d t<0$ and $\partial Q_{r 2}^{*} / \partial \gamma=$ $-\left(\partial L_{2}\left(Q_{r 2}^{*}\right) / \partial \gamma\right) /\left(\partial L_{2}\left(Q_{r 2}^{*}\right) / \partial Q_{r 2}^{*}\right)=0$; that is, the retailer's optimal firm order quantity under portfolio contracts is decreasing in $\alpha$ and constant in $\gamma$.

Corollary 9. The retailer's optimal total order quantity under portfolio contracts is decreasing in $\alpha$ and increasing in $\gamma$.

Proof. Let $L_{3}\left(Q_{2}^{*}\right)=\int_{0}^{T}\left(p e^{\gamma t}+g_{r}-c_{e}\right) \bar{F}\left(Q_{2}^{*}-\lambda e^{-\alpha t}\right) g(t) d t-$ $c_{o}$; we can derive that $\partial Q_{2}^{*} / \partial \alpha=-\left(\partial L_{3}\left(Q_{2}^{*}\right) / \partial \alpha\right) /$ $\left(\partial L_{3}\left(Q_{2}^{*}\right) / \partial Q_{2}^{*}\right)=-\int_{0}^{T} \lambda t e^{-\alpha t}\left(p e^{\gamma t}+g_{r}-c_{e}\right) f\left(Q_{2}^{*}-\right.$ $\left.\lambda e^{-\alpha t}\right) g(t) d t / \int_{0}^{T}\left(p e^{\gamma t}+g_{r}-c_{e}\right) f\left(Q_{2}^{*}-\lambda e^{-\alpha t}\right) g(t) d t<0$ and $\partial Q_{2}^{*} / \partial \gamma=-\left(\partial L_{3}\left(Q_{2}^{*}\right) / \partial \gamma\right) /\left(\partial L_{3}\left(Q_{2}^{*}\right) / \partial Q_{2}^{*}\right)=\int_{0}^{T} p t e^{\gamma t} \bar{F}\left(Q_{2}^{*}-\right.$ $\left.\lambda e^{-\alpha t}\right) g(t) d t / \int_{0}^{T}\left(p e^{\gamma t}+g_{r}-c_{e}\right) f\left(Q_{2}^{*}-\lambda e^{-\alpha t}\right) g(t) d t>0$; that is, the retailer's optimal total order quantity under portfolio contracts is decreasing in $\alpha$ and increasing in $\gamma$.

From Corollaries 8 and 9, we can see that when the rising degree of price runs faster than the falling degree of demand, the retailer will raise the total order quantity through increasing the options order quantity. It is worth noting that the retailer does not attempt to make any alteration in the firm order quantity under this situation. When the falling degree of demand runs faster than the rising degree of price, the retailer will reduce both the firm order quantity and the total order quantity.

4.3.2. Optimal Production Policy under Portfolio Contracts. Since the firm order is required to be delivered to the downstream retailer at the beginning of the selling period, the supplier's optimal production quantity cannot remain below the retailer's optimal firm order quantity under portfolio contracts. Moreover, since the retailer can obtain the additional products through the options order during the selling period and the options exercising quantity may not exceed the options order quantity, the supplier's optimal production quantity cannot surpass the retailer's optimal total order quantity under portfolio contracts. That is, $Q_{r 2}^{*} \leq Q_{s 2} \leq Q_{2}^{*}$. 
Under portfolio contracts, the optimal expected profit of the supplier, denoted as $\Pi_{s 2}\left(Q_{s 2}\right)$, is given by

$$
\begin{aligned}
& \Pi_{s 2}\left(Q_{s 2}\right)=\int_{0}^{T}\left\{w Q_{r 2}^{*}+c_{o}\left(Q_{2}^{*}-Q_{r 2}^{*}\right)\right. \\
& +c_{e} \min \left[\left(D(t)-Q_{r 2}^{*}\right)^{+}, Q_{2}^{*}-Q_{r 2}^{*}\right] \\
& \left.\quad-g_{s}\left[\min \left(D(t), Q_{2}^{*}\right)-Q_{s 2}\right]^{+}-c Q_{s 2}\right\} g(t) d t
\end{aligned}
$$

The first term is the revenue realized from firm orders. The second term is the revenue realized from options sales. The third term is the revenue realized from exercised options. The fourth term is the penalty cost and the last term is the production cost. Then, the above equation can be simplified as

$$
\begin{aligned}
\Pi_{s 2}\left(Q_{s 2}\right)= & \left(c_{o}+c_{e}-g_{s}\right) Q_{2}^{*} \\
& +\left(g_{s}-c_{e}\right) \int_{0}^{T} \int_{0}^{Q_{2}^{*}-\lambda e^{-\alpha t}} F(x) g(t) d x d t \\
& +\left(w-c_{o}-c_{e}\right) Q_{r 2}^{*} \\
& +c_{e} \int_{0}^{T} \int_{0}^{Q_{r 2}^{*}-\lambda e^{-\alpha t}} F(x) g(t) d x d t \\
& +\left(g_{s}-c\right) Q_{s 2} \\
& -g_{s} \int_{0}^{T} \int_{0}^{Q_{s 2}-\lambda e^{-\alpha t}} F(x) g(t) d x d t .
\end{aligned}
$$

The supplier's decision problem under portfolio contracts is described as

$$
\begin{array}{cl}
\max _{Q_{s 2}>0} & \Pi_{s 2}\left(Q_{s 2}\right) \\
\text { s.t. } & Q_{r 2}^{*} \leq Q_{s 2} \leq Q_{2}^{*} .
\end{array}
$$

As to the supplier's optimal production policy under portfolio contracts, we can derive the following proposition.

Proposition 10. Under portfolio contracts, the supplier's optimal production quantity $Q_{s 2}^{*}$ satisfies

$$
Q_{s 2}^{*}= \begin{cases}Q_{r 2}^{*} & Q_{s 2}^{\varphi} \leq Q_{r 2}^{*} \\ Q_{s 2}^{\varphi} & Q_{r 2}^{*}<Q_{s 2}^{\varphi}<Q_{2}^{*} \\ Q_{2}^{*} & Q_{s 2}^{\varphi} \geq Q_{2}^{*},\end{cases}
$$

where $\int_{0}^{T} F\left(Q_{s 2}^{\varphi}-\lambda e^{-\alpha t}\right) g(t) d t=\left(g_{s}-c\right) / g_{s}$.

Proof. From (19), we can derive that $d \Pi_{s 2}\left(Q_{s 2}\right) / d Q_{s 2}=\left(g_{s}-\right.$ c) $-g_{s} \int_{0}^{T} F\left(Q_{s 2}-\lambda e^{-\alpha t}\right) g(t) d t$ and $d^{2} \Pi_{s 2}\left(Q_{s 2}\right) / d Q_{s 2}^{2}=$ $-g_{s} \int_{0}^{T} f\left(Q_{s 2}-\lambda e^{-\alpha t}\right) g(t) d t<0$, so $\Pi_{s 2}\left(Q_{s 2}\right)$ is concave in $Q_{s 2}$. Let $d \Pi_{s 2}\left(Q_{s 2}\right) / d Q_{s 2}=0$; we can derive that the optimal solution to (19) is $\int_{0}^{T} F\left(Q_{s 2}^{\varphi}-\lambda e^{-\alpha t}\right) g(t) d t=\left(g_{s}-c\right) / g_{s}$.
Considering the constraint in (20), the supplier's optimal production quantity under portfolio contracts satisfies

$$
Q_{s 2}^{*}= \begin{cases}Q_{r 2}^{*} & Q_{s 2}^{\varphi} \leq Q_{r 2}^{*} \\ Q_{s 2}^{\varphi} & Q_{r 2}^{*}<Q_{s 2}^{\varphi}<Q_{2}^{*} \\ Q_{2}^{*} & Q_{s 2}^{\varphi} \geq Q_{2}^{*} .\end{cases}
$$

This proposition shows that, owing to the production constraint condition, the supplier's optimal production quantity under portfolio contracts is expressed as an interval. If $Q_{s 2}^{\varphi} \leq Q_{r 2}^{*}$, the constraint condition plays an important role in the production decision. At this point, the supplier will make every effort to reduce the production quantity so as to increase the expected profit. Obviously, the production quantity equivalent to the firm order quantity is the supplier's best choice. If $Q_{r 2}^{*}<Q_{s 2}^{\varphi}<Q_{2}^{*}$, the constraint condition plays no role in the production decision. If $Q_{s 2}^{\varphi} \geq Q_{2}^{*}$, the constraint condition plays an important role in the production decision. At this point, the supplier will try the best to raise the production quantity so as to increase the expected profit. Obviously, the production quantity equivalent to the total order quantity is the supplier's best choice. Moreover, this proposition also shows that the effect of inflation also has a significant impact on the supplier's optimal production policy under portfolio contracts. We have the following corollary.

Corollary 11. The supplier's optimal production quantity under portfolio contracts is decreasing in $\alpha$ and nondecreasing in $\gamma$.

Proof. Let $H_{2}\left(Q_{s 2}^{\varphi}\right)=\left(g_{s}-c\right)-g_{s} \int_{0}^{T} F\left(Q_{s 2}^{\varphi}-\lambda e^{-\alpha t}\right) g(t) d t$. From Proposition 10, we see that if $Q_{s 1}^{\varphi}<Q_{r 2}^{*}$, then $Q_{s 2}^{*}=Q_{r 2}^{*}$. The supplier's optimal production quantity is decreasing in $\alpha$ and constant in $\gamma$. If $Q_{r 2}^{*}<Q_{s 1}^{\varphi}<Q_{2}^{*}$, then $Q_{s 2}^{*}=Q_{s 2}^{\varphi}$. We can deduce that $\partial Q_{s 2}^{\varphi} / \partial \alpha=-\left(\partial H_{2}\left(Q_{s 2}^{\varphi}\right) / \partial \alpha\right) /\left(\partial H_{2}\left(Q_{s 2}^{\varphi}\right) / \partial Q_{s 2}^{\varphi}\right)=$ $-\int_{0}^{T} \lambda t e^{-\alpha t} f\left(Q_{s 2}^{\varphi}-\lambda e^{-\alpha t}\right) g(t) d t / \int_{0}^{T} f\left(Q_{s 2}^{\varphi}-\lambda e^{-\alpha t}\right) g(t) d t<$ 0 and $\partial Q_{s 2}^{\varphi} / \partial \gamma=-\left(\partial H_{2}\left(Q_{s 2}^{\varphi}\right) / \partial \gamma\right) /\left(\partial H_{2}\left(Q_{s 2}^{\varphi}\right) / \partial Q_{s 2}^{\varphi}\right)=0$, so in this case the supplier's optimal production quantity is decreasing in $\alpha$ and constant in $\gamma$. If $Q_{s 1}^{\varphi} \geq Q_{2}^{*}$, then $Q_{s 1}^{*}=Q_{2}^{*}$. The supplier's optimal production quantity is decreasing in $\alpha$ and increasing in $\gamma$. Hence, the supplier's optimal production quantity under portfolio contracts is decreasing in $\alpha$ and nondecreasing in $\gamma$.

From Corollary 11, we can see that when the rising degree of price runs faster than the falling degree of demand, the supplier will observe the operation status carefully and then decide whether to increase or maintain the production quantity. When the falling degree of demand runs faster than the rising degree of price, the supplier will reduce the production quantity. 


\section{The Impact of Option Contracts}

In this section, we plan to explore the impact of option contracts on supply chain through comparing with the results under different contracting arrangements.

\subsection{The Impact of Option Contracts on Supply Chain Decisions.} Comparing the retailer's optimal order quantity among these three different contracts, we consider the impact of option contracts on the retailer's ordering decision.

Proposition 12. The retailer's optimal order quantity under three different types of procurement contracts is as follows: the maximum is the optimal total order quantity under portfolio contracts and the optimal options order quantity under option contracts, the medium is the optimal firm order quantity under wholesale price contracts, and the minimum is the optimal firm order quantity under portfolio contracts. That is, $Q_{r 2}^{*}<Q_{r 0}^{*}<$ $q_{r 1}^{*}=Q_{2}^{*}$.

Proof. From (7) and (16), we can deduce that $q_{r 1}^{*}=Q_{2}^{*}$. From (3) and (15), we can deduce that $\left.\left(d \Pi_{r 0}\left(Q_{r 0}\right) / d Q_{r 0}\right)\right|_{Q_{r 0}=Q_{r 2}^{*}}=$ $\int_{0}^{T}\left(p e^{\gamma t}+g_{r}-w\right) g(t) d t-\int_{0}^{T}\left(p e^{\gamma t}+g_{r}\right) F\left(Q_{r 2}^{*}-\lambda e^{-\alpha t}\right) g(t) d t>$ $\left(w /\left(w-c_{o}\right)\right)\left[\left(c_{o}+c_{e}-w\right)-c_{e} \int_{0}^{T} F\left(Q_{r 2}^{*}-\lambda e^{-\alpha t}\right) g(t) d t\right]=0$. Recalling that $\Pi_{r 0}\left(Q_{r 0}\right)$ is concave in $Q_{r 0}$, it follows that $Q_{r 0}^{*}>$ $Q_{r 2}^{*}$.

From (3) and (7), we can deduce that $\left.\left(d \Pi_{r 1}\left(q_{r 1}\right) / d q_{r 1}\right)\right|_{q_{r 1}=Q_{r 0}^{*}}=\int_{0}^{T}\left(p e^{\gamma t}+g_{r}-w\right) g(t) d t-$ $\int_{0}^{T}\left(p e^{\gamma t}+g_{r}\right) F\left(Q_{r 0}^{*}-\lambda e^{-\alpha t}\right) g(t) d t-\left(c_{o}+c_{e}-w\right)+c_{e} \int_{0}^{T} F\left(Q_{r 0}^{*}-\right.$ $\left.\lambda e^{-\alpha t}\right) g(t) d t>0$. Recalling that $\Pi_{r 1}\left(q_{r 1}\right)$ is concave in $q_{r 1}$, it follows that $q_{r 1}^{*}>Q_{r 0}^{*}$. So, $Q_{r 2}^{*}<Q_{r 0}^{*}<q_{r 1}^{*}=Q_{2}^{*}$.

Proposition 12 explains the change that occurs in the retailer's optimal ordering policy after introducing option contracts under inflation scenarios. Since the same market environment is faced, the retailer's optimal options order quantity under option contracts is equivalent to the retailer's optimal total order quantity under portfolio contracts. Moreover, since call options give only the right, but not the obligation, to obtain the products, the retailer can choose to exercise call options or not use them at all. Obviously, the presence of option contracts provides more flexibility for the retailer than wholesale price contracts. Thus, the optimal aggregate order quantity under portfolio contracts is always higher than the optimal firm order quantity under wholesale price contracts. In addition, the optimal options order quantity under option contracts is always higher than the optimal firm order quantity under wholesale price contracts. In other words, comparing with the case of wholesale price contracts, the retailer will increase the order quantity so as to reduce the shortage cost caused by unsatisfied demand in the presence of option contracts. Furthermore, call options give the retailer the right to adjust the order quantity upwards. Obviously, the presence of option contracts will suppress the retailer's purchasing behavior and restrains increasing the firm order quantity. Thus, the optimal firm order quantity under wholesale price contracts is higher than that under portfolio contracts.

Contrasting the supplier's optimal production quantity among these three different contracts, we consider the impact of option contracts on the supplier's production decision.

Proposition 13. If $Q_{s}^{\varphi} \in\left(0, Q_{r 2}^{*}\right)$, then $Q_{s 1}^{*}<Q_{s 2}^{*}<Q_{s 0}^{*}$. If $Q_{s}^{\varphi} \in\left(Q_{r 2}^{*}, Q_{r 0}^{*}\right)$, then $Q_{s 1}^{*}=Q_{s 2}^{*}<Q_{s 0}^{*}$. If $Q_{s}^{\varphi} \in\left(Q_{r 0}^{*},+\infty\right)$, then $Q_{s 1}^{*}=Q_{s 2}^{*}>Q_{s 0}^{*}$.

Proof. Let $Q_{s}^{\varphi}=Q_{s 1}^{\varphi}=Q_{s 2}^{\varphi}$. From Propositions 5 and 10, we can derive the following conclusions. If $Q_{s}^{\varphi} \in\left(0, Q_{r 2}^{*}\right)$, then $Q_{s 1}^{*}=Q_{s}^{\varphi}$ and $Q_{s 2}^{*}=Q_{r 2}^{*}$. We can obtain $Q_{s 1}^{*}<Q_{s 2}^{*}<Q_{s 0}^{*}$. If $Q_{s 2}^{\varphi} \in\left(Q_{r 2}^{*}, Q_{r 0}^{*}\right)$, then $Q_{s 1}^{*}=Q_{s}^{\varphi}$ and $Q_{s 2}^{*}=Q_{s}^{\varphi}$. We can obtain $Q_{s 1}^{*}=Q_{s 2}^{*}<Q_{s 0}^{*}$. If $Q_{s}^{\varphi} \in\left(Q_{r 0}^{*}, Q_{2}^{*}\right)$, then $Q_{s 1}^{*}=Q_{s}^{\varphi}$ and $Q_{s 2}^{*}=$ $Q_{s}^{\varphi}$. We can obtain $Q_{s 1}^{*}=Q_{s 2}^{*}>Q_{s 0}^{*}$. If $Q_{s}^{\varphi} \in\left(Q_{2}^{*},+\infty\right)$, then $Q_{s 1}^{*}=q_{r 1}^{*}$ and $Q_{s 2}^{*}=Q_{2}^{*}$. We can obtain $Q_{s 1}^{*}=Q_{s 2}^{*}>Q_{s 0}^{*}$.

Proposition 13 explains the change that occurs in the supplier's optimal production policy after introducing option contracts under inflation scenarios. Owing to the production constraint condition, the supplier's production decision becomes more complicated but more flexible after introducing option contracts. Moreover, the supplier's optimal production quantity under portfolio contracts is not less than that under option contracts. The main reason is that the supplier must deliver the firm order at the beginning of the selling period under portfolio contracts. In contrast, the supplier does not need to deliver a certain quantity of products at the beginning of the selling period under option contracts.

Now we summarize the conclusions regarding the impact of option contracts on the supply chain members' optimal decision policies under inflation scenarios in Table 1 .

Table 1 shows that the introduction of option contracts will suppress the urge to buy more products and make the retailer decrease the size of the firm order under inflation scenarios. Moreover, the introduction of option contracts will prompt increasing the size of the total order and help the retailer reduce the shortage risk under inflation scenarios. Furthermore, the introduction of option contracts will contribute to adjusting the production quantity and make the supplier more flexible under inflation scenarios.

5.2. The Impact of Option Contracts on Supply Chain Performance. Comparing the retailer's optimal expected profit among these three different contracts, we examine the impact of option contracts on the retailer's performance.

Proposition 14. The retailer's optimal expected profit under three different types of procurement contracts is as follows: the maximum is that under portfolio contracts, the medium is that under option contracts, and the minimum is that under wholesale price contracts. That is, $\Pi_{r 0}\left(Q_{r 0}^{*}\right)<\Pi_{r 1}\left(q_{r 1}^{*}\right)<$ $\Pi_{r 2}\left(Q_{r 2}^{*}, Q_{2}^{*}\right)$.

Proof. First, we compare $\Pi_{r 2}\left(Q_{r 2}^{*}, Q_{2}^{*}\right)$ with $\Pi_{r 1}\left(q_{r 1}^{*}\right)$. Let $\Delta_{1}\left(Q_{r 2}^{*}\right)=\Pi_{r 2}\left(Q_{r 2}^{*}, Q_{2}^{*}\right)-\Pi_{r 1}\left(q_{r 1}^{*}\right)$; we can derive that $\Delta_{1}\left(Q_{r 2}^{*}\right)=\left(c_{o}+c_{e}-w\right) Q_{r 2}^{*}-c_{e} \int_{0}^{T} \int_{0}^{Q_{r 2}^{*}-\lambda e^{-\alpha t}} F(x) g(t) d x d t$. 
TABLE 1: The impact of option contracts on supply chain decisions.

\begin{tabular}{lccc}
\hline & Wholesale price contracts & Option contracts & Portfolio contracts \\
\hline Optimal firm order quantity & Maximum & - & Minimum \\
Optimal options order quantity & - & Maximum & Minimum \\
Optimal total order quantity & Minimum & & Maximum \\
Optimal production quantity & Fixed value & Interval value & Interval value \\
\hline
\end{tabular}

Because $\Delta_{1}(0)=0$ and $\left.\left(d \Delta_{1}\left(Q_{r 2}^{*}\right) / d Q_{r 2}^{*}\right)\right|_{Q_{r 2}^{*}=0}>0$, we can obtain that $\Pi_{r 2}\left(Q_{r 2}^{*}, Q_{2}^{*}\right)>\Pi_{r 1}\left(q_{r 1}^{*}\right)$. Then, we compare $\Pi_{r 1}\left(q_{r 1}^{*}\right)$ with $\Pi_{r 0}\left(Q_{r 0}^{*}\right)$. Let $\Delta_{2}\left(Q_{r 0}^{*}\right)=\Pi_{r 1}\left(Q_{r 0}^{*}\right)$ $\Pi_{r 0}\left(Q_{r 0}^{*}\right)$; we derive that $\Delta_{2}\left(Q_{r 0}^{*}\right)=\left(w-c_{o}-c_{e}\right) Q_{r 0}^{*}+$ $c_{e} \int_{0}^{T} \int_{0}^{Q_{r 0}^{*}-\lambda e^{-\alpha t}} F(x) g(t) d x d t$. Because $\Delta_{2}(0)=0$ and $d \Delta_{2}\left(Q_{r 0}^{*}\right) / d Q_{r 0}^{*}=-c_{e}\left[\int_{0}^{T} F\left(Q_{r 2}^{*}-\lambda e^{-\alpha t}\right) g(t) d t-\int_{0}^{T} F\left(Q_{r 0}^{*}-\right.\right.$ $\left.\left.\lambda e^{-\alpha t}\right) g(t) d t\right]>0$, we obtain that $\Pi_{r 1}\left(Q_{r 0}^{*}\right)>\Pi_{r 0}\left(Q_{r 0}^{*}\right)$. Since $\Pi_{r 1}\left(q_{r 1}^{*}\right)>\Pi_{r 1}\left(Q_{r 0}^{*}\right)$, we obtain that $\Pi_{r 1}\left(q_{r 1}^{*}\right)>\Pi_{r 0}\left(Q_{r 0}^{*}\right)$.

Proposition 14 explains the change that occurs in the retailer's optimal expected profit after introducing option contracts under inflationary conditions. Since call options give the right to obtain the products based on the realized market demand, the retailer can adjust the order quantity upwards in the presence of option contracts. Obviously, the introduction of option contracts brings more benefits to the retailer than wholesale price contracts. Thus, the retailer's optimal expected profit under wholesale price contracts is lower than that under the other two contracts. Moreover, we can see that wholesale price contracts are characterized by only one parameter, unit wholesale price of products. Option contracts are characterized by two parameters: one is unit purchase price of call options and the other is unit exercise price of call options. Since $c_{o}+c_{e}>w$ and $q_{r 1}^{*}=Q_{2}^{*}$, the retailer's procurement cost under portfolio contracts is always lower than that under option contracts. Thus, the retailer's optimal expected profit under portfolio contracts is higher than that under option contracts. In conclusion, portfolio contracts are the most preferable for the retailer among these three different contracts under inflation scenarios.

Comparing the supplier's optimal expected profit among these three different contracts, we examine the impact of option contracts on the supplier's performance.

Proposition 15. The supplier's optimal expected profit under three different types of procurement contracts is as follows: the maximum profit is that under option contracts, the medium is that under portfolio contracts, and the minimum is that under wholesale price contracts. That is, $\Pi_{s 0}\left(Q_{s 0}^{*}\right)<\Pi_{s 2}\left(Q_{s 2}^{*}\right)<$ $\Pi_{s 1}\left(Q_{s 1}^{*}\right)$.

Proof. First, we compare $\Pi_{s 1}\left(Q_{s 1}^{*}\right)$ with $\Pi_{s 2}\left(Q_{s 2}^{*}\right)$. Let $\Delta_{3}\left(Q_{r 2}^{*}\right)=\Pi_{s 1}\left(Q_{s 1}^{*}\right)-\Pi_{s 2}\left(Q_{s 2}^{*}\right)$; we can derive that $\Delta_{3}\left(Q_{r 2}^{*}\right)=\left(c_{o}+c_{e}-w\right) Q_{r 2}^{*}-c_{e} \int_{0}^{T} \int_{0}^{Q_{r 2}^{*}-\lambda e^{-\alpha t}} F(x) g(t) d x d t-$ $\left(g_{s}-c\right)\left(Q_{s 2}^{*}-Q_{s 1}^{*}\right)+g_{s} \int_{0}^{T} \int_{Q_{s 1}^{*}-\lambda e^{-\alpha t}}^{Q^{*}-\lambda(x)} F(t) d x d t$. From the previous analysis, we can see that $\left(c_{o}+c_{e}-w\right) Q_{r 2}^{*}-$ $c_{e} \int_{0}^{T} \int_{0}^{Q_{r 2}^{*}-\lambda e^{-\alpha t}} F(x) g(t) d x d t>0$. Now let $Q_{s}^{\varphi}=Q_{s 1}^{\varphi}=Q_{s 2}^{\varphi}$.
If $Q_{s}^{\varphi} \in\left(Q_{r 2}^{*},+\infty\right)$, then $Q_{s 1}^{*}=Q_{s 2}^{*}$ and $-\left(g_{s}-c\right)\left(Q_{s 2}^{*}-\right.$ $\left.Q_{s 1}^{*}\right)+g_{s} \int_{0}^{T} \int_{Q_{s 1}^{*}-\lambda e^{-\alpha t}}^{Q_{2}^{*}-\lambda e^{-\alpha t}} F(x) g(t) d x d t=0$. We can obtain that $\Delta_{3}\left(Q_{r 2}^{*}\right)>0$. If $Q_{s}^{\varphi} \in\left(Q_{r 2}^{*},+\infty\right)$, then $Q_{s 1}^{*}<Q_{s 2}^{*}$ and $-\left(g_{s}-c\right)\left(Q_{s 2}^{*}-Q_{s 1}^{*}\right)+g_{s} \int_{0}^{T} \int_{Q_{s 1}^{*}-\lambda e^{-\alpha t}}^{Q_{s}^{*}-\lambda e^{-\alpha t}} F(x) g(t) d x d t>0$. We can obtain that $\Delta_{3}\left(Q_{r 2}^{*}\right)>0$. Hence $\Pi_{s 1}\left(Q_{s 1}^{*}\right)>\Pi_{s 2}\left(Q_{s 2}^{*}\right)$.

Then, we compare $\Pi_{s 2}\left(Q_{s 2}^{*}\right)$ with $\Pi_{s 0}\left(Q_{s 0}^{*}\right)$. Let $\Delta_{4}(w)=$ $\Pi_{s 2}\left(Q_{s 2}^{*}\right)-\Pi_{s 0}\left(Q_{s 0}^{*}\right)$; we can derive that $\Delta_{4}(w)=(w-$ $\left.c_{o}-c_{e}\right) Q_{r 2}^{*}+c_{e} \int_{0}^{T} \int_{0}^{Q_{r 2}^{*}-\lambda e^{-\alpha t}} F(x) g(t) d x d t+\left(c_{o}+c_{e}-\right.$ $\left.g_{s}\right) Q_{2}^{*}+\left(g_{s}-c_{e}\right) \int_{0}^{T} \int_{0}^{Q_{2}^{*}-\lambda e^{-\alpha t}} F(x) g(t) d x d t+\left(g_{s}-c\right) Q_{s 2}^{*}-$ $g_{s} \int_{0}^{T} \int_{0}^{Q_{s 2}^{*}-\lambda e^{-\alpha t}} F(x) g(t) d x d t-(w-c) Q_{r 0}^{*}$. Let $w^{0}=c_{o}\left(p e^{\gamma t}+\right.$ $\left.g_{r}\right) /\left(p e^{\gamma t}+g_{r}-c_{e}\right)$. If $w=w^{0}$, then $q_{r 2}^{*}=0, Q_{r 2}^{*}=$ $Q_{2}^{*}=Q_{r 0}^{*}$, and $Q_{s 2}^{*}=Q_{r 0}^{*}$. We can see that $\Delta_{4}(w) \stackrel{Q^{2}}{=} 0$. Notice $\left.\left(d \Delta_{4}(w) / d w\right)\right|_{w=w^{0}}=g_{s}\left[\int_{0}^{T} F\left(Q_{s 2}^{\varphi}-\lambda e^{-\alpha t}\right) g(t) d t-\right.$ $\left.\int_{0}^{T} F\left(Q_{s 2}^{*}-\lambda e^{-\alpha t}\right) g(t) d t\right]\left(d Q_{s 2}^{*} / d w\right)-\left(w^{0}-c\right)\left(d Q_{r 0}^{*} / d w\right)$. From (3), we can see that $Q_{r 0}^{*}$ is decreasing in $w$. If $Q_{s 2}^{\varphi}>Q_{r 2}^{*}$, then $d Q_{s 2}^{*} / d w=0$. We can obtain that $\left.\left(d \Delta_{4}(w) / d w\right)\right|_{w=w^{0}}>0$. If $Q_{s 2}^{\varphi} \leq Q_{r 2}^{*}$, then $Q_{s 2}^{*}=Q_{r 2}^{*}, \int_{0}^{T} F\left(Q_{s 2}^{\varphi}-\lambda e^{-\alpha t}\right) g(t) d t \leq$ $\int_{0}^{T} F\left(Q_{s 2}^{*}-\lambda e^{-\alpha t}\right) g(t) d t$, and $d Q_{s 2}^{*} / d w<0$. We can obtain that $\left.\left(d \Delta_{4}(w) / d w\right)\right|_{w=w^{0}}>0$. Hence $\Pi_{s 2}\left(Q_{s 2}^{*}\right)>\Pi_{s 0}\left(Q_{s 0}^{*}\right)$.

Proposition 15 explains the change that occurs in the supplier's optimal expected profit after introducing option contracts under inflation scenarios. When wholesale price contracts are employed, the supplier determines how many products to manufacture based on the retailer's firm order. When option contracts or portfolio contracts are employed, the supplier can determine the production quantity that maximizes its own interest based on the retailer's flexible purchasing. Obviously, the introduction of option contracts brings more benefits to the supplier than wholesale price contracts. Moreover, since there is no constraint for the minimum production quantity, the supplier can plan the production schedule with more flexibility under option contracts through comparing with the case of portfolio contracts. Thus, the supplier's optimal expected profit under option contracts is higher than that under portfolio contracts. In conclusion, option contracts are the most preferable for the supplier among the three different contracts under inflation scenarios. Furthermore, owing to the supplier's market dominant position, the supply chain is willing to implement option contracts ultimately.

Now we summarize the conclusions regarding the impact of option contracts on the supply chain members' optimal expected profit under inflation scenarios in Table 2. 
TABLE 2: The impact of option contracts on supply chain performance.

\begin{tabular}{lccc}
\hline & Wholesale price contracts & Option contracts & Portfolio contracts \\
\hline Retailer's optimal expected profit & Minimum & Medium & Maximum \\
Supplier's optimal expected profit & Minimum & Maximum & Medium \\
\hline
\end{tabular}

Table 2 shows that the introduction of option contracts benefits both the supplier and the retailer. Obviously, the presence of option contracts is a good thing for the supply chain members under inflation scenarios. Moreover, the retailer prefers ordering products and purchasing call options, but the supplier is only inclined to provide call options under inflation scenarios. Furthermore, the supply chain will implement option contracts ultimately under inflation scenarios.

\section{Supply Chain Bilateral Coordination}

In this section, we plan to study how to design option contract mechanism to achieve supply chain coordination under inflation scenarios.

To derive the optimal expected profit of the supply chain, we take the channel as a centralized entity and consider a central controller which decides the production quantity $Q_{I}$. The expected profit of the supply chain, denoted as $\Pi_{I}\left(Q_{I}\right)$, is given by

$$
\begin{array}{r}
\Pi_{I}\left(Q_{I}\right)=\int_{0}^{T}\left\{p(t) \min \left[D(t), Q_{I}\right]\right. \\
\left.-g_{r}\left[D(t)-Q_{I}\right]^{+}-c Q_{I}\right\} g(t) d t .
\end{array}
$$

The first term is the sales revenue. The second term is the shortage cost, and the last term is the production cost. Then, the above equation can be simplified as

$$
\begin{aligned}
& \Pi_{I}\left(Q_{I}\right) \\
& =Q_{I} \int_{0}^{T}\left(p e^{\gamma t}+g_{r}-c\right) g(t) d t \\
& \quad-g_{r} \int_{0}^{T} \lambda e^{-\alpha t} g(t) d t-g_{r} \mu \\
& \quad-\int_{0}^{T} \int_{0}^{Q_{I}-\lambda e^{-\alpha t}}\left(p e^{\gamma t}+g_{r}\right) F(x) g(t) d x d t .
\end{aligned}
$$

As to the optimal production policy of the supply chain system under centralized decision-making, we can derive the following proposition.

Proposition 16. The central controller's optimal production quantity $Q_{I}^{*}$ is

$$
\int_{0}^{T}\left(p e^{\gamma t}+g_{r}\right) \bar{F}\left(Q_{I}^{*}-\lambda e^{-\alpha t}\right) g(t) d t=c .
$$

Proof. From (24), we can derive that $d \Pi_{I}\left(Q_{I}\right) / d Q_{I}=$ $\int_{0}^{T}\left(p e^{\gamma t}+g_{r}-c\right) g(t) d t-\int_{0}^{T}\left(p e^{\gamma t}+g_{r}\right) F\left(Q_{I}-\lambda e^{-\alpha t}\right) g(t) d t$ and $d^{2} \Pi_{I}\left(Q_{I}\right) / d Q_{I}^{2}=-\int_{0}^{T}\left(p e^{\gamma t}+g_{r}\right) f\left(Q_{I}-\lambda e^{-\alpha t}\right) g(t) d t<0$, so $\Pi_{I}\left(Q_{I}\right)$ is concave in $Q_{I}$. Let $d \Pi_{I}\left(Q_{I}\right) / d Q_{I}=0$; we can obtain that the optimal solution to $(24)$ is $\int_{0}^{T}\left(p e^{\gamma t}+g_{r}\right) \bar{F}\left(Q_{I}^{*}-\right.$ $\left.\lambda e^{-\alpha t}\right) g(t) d t=c$.

From the analysis above, we see that the supply chain will implement option contracts ultimately under inflation scenarios. In the remaining part, we plan to discuss how option contracts should be set to attain supply chain coordination under inflation scenarios.

As we know, the supplier is always assumed to commit to manufacturing the products up to the retailer's order in the tradition approach [36]. In this case, the issue on how to make a noncentralized supply chain achieve coordination can be simplified to the unilateral coordination from the retailer's perspective only. However, the supplier does not comply with the make-to-order policy and decides the production quantity according to the profit maximization rule under option contracts. The supply chain coordination cannot be achieved according to the tradition unilateral coordination mechanism. Similar to Chen et al. [26, 30], we design the bilateral coordination mechanism from both the retailer's and the supplier's perspectives.

Proposition 17. When $g_{s}>p e^{\gamma t}+g_{r}-c_{e}$ and $\int_{0}^{T} F\left(Q_{I}^{*}-\right.$ $\left.\lambda e^{-\alpha t}\right) g(t) d t=\left(c_{o}+c_{e}-c\right) / c_{e}$ are satisfied, the supply chain with option contracts can be coordinated under inflation scenarios.

Proof. Since the supplier decides the optimal production quantity that maximizes its own profit under option contracts, both the retailer's order quantity and the supplier's production quantity need coordinate. Both Propositions 5 and 16 provide a condition to motivate the supplier to produce the same quantity as that in the coordinated supply chain. Then $Q_{s 1}^{\varphi} \geq q_{r 1}^{*}$; that is, $g_{s}>p e^{\gamma t}+g_{r}-c_{e}$. From Propositions 3 and 16, we can see that, to ensure the retailer's order is coordinated, the retailer's order quantity must satisfy $\int_{0}^{T}\left(p e^{\gamma t}+g_{r}-c_{e}\right) \bar{F}\left(Q_{I}^{*}-\lambda e^{-\alpha t}\right) g(t) d t=c_{o}$. From (25), we can derive that $\int_{0}^{T} F\left(Q_{I}^{*}-\lambda e^{-\alpha t}\right) g(t) d t=\left(c_{o}+c_{e}-c\right) / c_{e}$. The two aforementioned conditions are the supply chain coordination conditions.

Proposition 17 shows the sufficient conditions for the supply chain coordination. Let $=\Pi_{I}\left(Q_{I}^{*}\right)-\Pi_{r 1}\left(q_{r 1}^{*}\right)$; then we can obtain that $\Delta \pi=\left(c_{o}+c_{e}-c\right) Q_{I}^{*}-c_{e} \int_{0}^{T} \int_{0}^{Q_{I}^{*}-\lambda e^{-\alpha t}} F(x) g(t) d x d t$. Now let $\eta=\Delta \pi / \Pi_{I}\left(Q_{I}^{*}\right)(0<\eta<1)$. We can deduce that the expected profits of the supplier and the retailer after coordinating are $\Pi_{s 1}=\eta \Pi_{I}$ and $\Pi_{r 1}=(1-\eta) \Pi_{I}$, respectively. This implies that the supply chain coordination can be achieved through option contracts and the expected profit of the channel can be allocated arbitrarily between the supplier and the retailer under inflationary conditions. 
TABLE 3: The impact of $\gamma$ on the optimal decisions.

\begin{tabular}{lccccccc}
\hline$\gamma$ & $Q_{r 0}^{*}$ & $q_{r 1}^{*}$ & $Q_{r 2}^{*}$ & $q_{r 2}^{*}$ & $Q_{s 0}^{*}$ & $Q_{s 1}^{*}$ & $Q_{s 2}^{*}$ \\
\hline 0.0005 & 156.04 & 165.7 & 99.42 & 66.28 & 156.04 & 165.7 & 165.7 \\
0.001 & 156.19 & 165.78 & 99.42 & 66.36 & 156.19 & 165.78 \\
0.0015 & 156.35 & 165.86 & 99.42 & 66.44 & 156.35 & 165.86 \\
0.002 & 156.5 & 165.93 & 99.42 & 66.51 & 156.5 & 165.93 & 165.86 \\
0.0025 & 156.65 & 166 & 99.42 & 66.58 & 156.65 & 166 & 165.93 \\
0.003 & 156.8 & 166.08 & 99.42 & 66.66 & 156.8 & 166.08 & 166.08 \\
0.0035 & 156.95 & 166.15 & 99.42 & 66.73 & 156.95 & 166.15 \\
0.004 & 157.1 & 166.22 & 99.42 & 66.8 & 157.1 & 166.22 \\
0.0045 & 157.25 & 166.29 & 99.42 & 66.87 & 157.25 & 166.29 \\
0.005 & 157.4 & 166.36 & 99.42 & 66.94 & 157.4 & 16.15 \\
0.0055 & 157.54 & 166.43 & 99.42 & 67.01 & 157.54 & 166.36 \\
0.006 & 157.69 & 166.5 & 99.42 & 67.08 & 157.69 & 166.43 \\
0.0065 & 157.84 & 166.57 & 99.42 & 67.15 & 157.84 & 166.29 \\
0.007 & 157.99 & 166.64 & 99.42 & 67.22 & 157.99 & 169.36 \\
0.0075 & 158.13 & 166.7 & 99.42 & 67.28 & 158.13 & 166.43 \\
\hline
\end{tabular}

This proposition also shows that the supply chain coordination conditions are determined by the unit purchase price of call option $c_{o}$, unit exercise price of call option $c_{e}$, and unit production cost $c$ are not related to unit wholesale price $w$. This indicates that the unit wholesale price cannot be used to control the division of profit between the two members involved under option contracts and cannot influence the expected profit of the supply chain. Moreover, we can see that unit purchase price of call option is negatively related to unit exercise price of call option in the coordinating contracts. The main reason is that if there is an increase in both unit purchase price and unit exercise price, this presents an advantage to the supplier and a disadvantage to the retailer. Only when there is an inverse relationship between unit purchase price and unit exercise price, it is feasible to reconcile the conflicting interests between the retailer and the supplier under option contracts. Furthermore, we can observe that, with the coordinating contracts, the expected profits of each party do not decrease and at least one of them is strictly better off. Compared with the case of noncoordinating contracts, there always exists a Pareto contract.

\section{Numerical Example}

In this section, a numerical example is provided to illustrate the impact of inflation on the optimal decisions and the optimal expected profits.

We assume that the default values of parameters are used as $p=10, w=4, c=1.2, c_{o c}=2, c_{e c}=2.5, g_{s}=20$, $g_{r}=7, \lambda=100, T=60, t \sim U(0,60)$, and $\xi \sim U(0,100)$. The above values of parameters satisfy the basic assumptions of this paper.

7.1. The Impact of Inflation on the Optimal Decisions. The impact of price rising factor $(\gamma)$ on the optimal decisions is shown in Table 3.

From Table 3, the following observations can be obtained. On the one hand, the scale of market demand will increase when there is an obvious increase in $\gamma$, which will cause the following. (1) The retailer will increase the optimal firm order quantity under wholesale price contracts. (2) The retailer will increase the optimal options order quantity under option contracts. (3) The retailer will increase the optimal options order quantity and leave the optimal firm order quantity unchanged under portfolio contracts. On the other hand, the retailer's order requirement will increase when there is an obvious increase in $\gamma$, which will cause the supplier to increase the optimal production quantity with and without option contracts.

The impact of demand contraction factor $(\alpha)$ on the optimal decisions is shown in Table 4.

From Table 4, the following observations can be obtained. On the one hand, the scale of market demand will decline when there is an obvious increase in $\alpha$, which will cause the following. (1) The retailer will decrease the optimal firm order quantity under wholesale price contracts. (2) The retailer will decrease the optimal options order quantity under option contracts. (3) The retailer will decrease both the optimal options order quantity and the optimal firm order quantity under portfolio contracts. On the other hand, the retailer's order requirement will decrease when there is an obvious increase in $\alpha$, which will cause the supplier to decrease the optimal production quantity with and without option contracts.

From Tables 3 and 4, we can deduce the following conclusions. (1) Comparing with the case of wholesale price contracts, the introduction of option contracts will make the retailer raise the total ordering quantity and reduce the firm order quantity under inflation scenarios. (2) Comparing with the case of wholesale price contracts, the introduction of option contracts will make the supplier raise the production quantity under inflation scenarios.

7.2. The Impact of Inflation on the Optimal Expected Profits. The impact of price rising factor $(\gamma)$ on the optimal expected profits is shown in Table 5. 
TABLE 4: The impact of $\alpha$ on the optimal decisions.

\begin{tabular}{lccccccc}
\hline$\alpha$ & $Q_{r 0}^{*}$ & $q_{r 1}^{*}$ & $Q_{r 2}^{*}$ & $q_{r 2}^{*}$ & $Q_{s 0}^{*}$ & $Q_{s 1}^{*}$ \\
\hline 0.0085 & 157.15 & 165.63 & 98.33 & 67.29 & 157.15 & 165.63 \\
0.009 & 156.04 & 164.51 & 97.27 & 67.24 & 156.04 & 164.51 & 165.63 \\
0.0095 & 154.95 & 163.42 & 96.22 & 67.19 & 154.95 & 163.42 \\
0.01 & 153.88 & 162.34 & 95.2 & 67.15 & 153.88 & 162.34 & 164.51 \\
0.0105 & 152.83 & 161.29 & 94.19 & 67.1 & 152.83 & 161.29 & 162.34 \\
0.011 & 151.81 & 160.26 & 93.2 & 67.05 & 151.81 & 160.26 \\
0.0115 & 150.8 & 159.25 & 92.24 & 67.01 & 150.8 & 159.25 \\
0.012 & 149.81 & 158.25 & 91.28 & 66.97 & 149.81 & 168.29 \\
0.0125 & 148.85 & 157.28 & 90.35 & 66.93 & 148.85 & 158.25 \\
0.013 & 147.9 & 156.33 & 89.44 & 66.89 & 147.9 & 157.28 \\
0.0135 & 146.96 & 155.39 & 88.54 & 66.85 & 146.96 & 156.33 \\
0.014 & 146.05 & 154.47 & 87.65 & 66.82 & 146.05 & 155.39 \\
0.0145 & 145.15 & 153.57 & 86.79 & 66.78 & 145.15 & 154.47 \\
0.015 & 144.27 & 152.68 & 85.94 & 66.75 & 144.27 & 157.25 \\
0.0155 & 143.41 & 151.82 & 85.1 & 66.71 & 143.41 & 156.33 \\
\hline
\end{tabular}

TABLE 5: The impact of $\gamma$ on the optimal expected profits.

\begin{tabular}{|c|c|c|c|c|c|c|}
\hline$\gamma$ & $\Pi_{r 0}\left(Q_{r 0}^{*}\right)$ & $\Pi_{r 1}\left(q_{r 1}^{*}\right)$ & $\Pi_{r 2}\left(Q_{r 2}^{*}, Q_{2}^{*}\right)$ & $\Pi_{s 0}\left(Q_{s 0}^{*}\right)$ & $\Pi_{s 1}\left(Q_{s 1}^{*}\right)$ & $\Pi_{s 2}\left(Q_{s 2}^{*}\right)$ \\
\hline 0.0005 & 631.69 & 635.41 & 678.61 & 280.88 & 452.25 & 409.05 \\
\hline 0.001 & 650.43 & 654.32 & 697.53 & 281.15 & 452.34 & 409.14 \\
\hline 0.0015 & 669.55 & 673.62 & 716.82 & 281.42 & 452.43 & 409.23 \\
\hline 0.002 & 689.04 & 693.29 & 736.50 & 281.69 & 452.51 & 409.31 \\
\hline 0.0025 & 708.94 & 713.37 & 756.57 & 281.96 & 452.6 & 409.39 \\
\hline 0.003 & 729.23 & 733.84 & 777.04 & 282.23 & 452.68 & 409.48 \\
\hline 0.0035 & 749.94 & 754.73 & 797.93 & 282.5 & 452.76 & 409.56 \\
\hline 0.004 & 771.07 & 776.03 & 819.24 & 282.77 & 452.84 & 409.64 \\
\hline 0.0045 & 792.63 & 797.77 & 840.97 & 283.04 & 452.92 & 409.72 \\
\hline 0.005 & 814.64 & 819.95 & 863.15 & 283.31 & 453.00 & 409.8 \\
\hline 0.0055 & 837.09 & 842.58 & 885.78 & 283.58 & 453.08 & 409.88 \\
\hline 0.006 & 860.00 & 865.66 & 908.87 & 283.85 & 453.16 & 409.96 \\
\hline 0.0065 & 883.39 & 889.22 & 932.42 & 284.11 & 453.23 & 410.03 \\
\hline 0.007 & 907.26 & 913.26 & 956.47 & 284.37 & 453.31 & 410.11 \\
\hline 0.0075 & 931.62 & 937.80 & 981.00 & 284.64 & 453.38 & 410.18 \\
\hline
\end{tabular}

From Table 5, the following observations can be obtained. On the one hand, when there is an obvious increase in $\gamma$, the scale of market demand increases which will cause the retailer to obtain more profit with and without option contracts. On the other hand, when there is an obvious increase in $\gamma$, the retailer's order requirement increases which will cause the supplier to obtain more profit with and without option contracts.

The impact of demand contraction factor $(\alpha)$ on the optimal expected profits is shown in Table 6.

From Table 6, the following observations can be obtained. On the one hand, when there is an obvious increase in $\alpha$, the scale of market demand declines which will cause the retailer to obtain less profit with and without option contracts. On the other hand, when there is an obvious increase in $\alpha$, the retailer's order requirement decreases which will cause the supplier to obtain less profit with and without option contracts.
From Tables 5 and 6, we can deduce the following conclusions. (1) Comparing with the case of wholesale price contracts, the introduction of option contracts will make both the retailer and the supplier obtain more profits under inflation scenarios. (2) Among the three different contracts, the retailer prefers portfolio contracts and the supplier prefers option contracts under inflation scenarios.

\section{Conclusion}

Most countries in the world have suffered from different degrees of inflation for years. The effect of inflation exerts an important influence on supply chain management. In this context, the studies on how to use various contracts to protect against the effect of inflation and achieve a coordinated channel are very meaningful. To the best of our knowledge, most papers focus on how to use various contracts to manage demand uncertainty. So far, the effect of 
TABLE 6: The impact of $\alpha$ on the optimal expected profits.

\begin{tabular}{|c|c|c|c|c|c|c|}
\hline$\alpha$ & $\Pi_{r 0}\left(Q_{r 0}^{*}\right)$ & $\Pi_{r 1}\left(q_{r 1}^{*}\right)$ & $\Pi_{r 2}\left(Q_{r 2}^{*}, Q_{2}^{*}\right)$ & $\Pi_{s 0}\left(Q_{s 0}^{*}\right)$ & $\Pi_{s 1}\left(Q_{s 1}^{*}\right)$ & $\Pi_{s 2}\left(Q_{s 2}^{*}\right)$ \\
\hline 0.0085 & 945.02 & 951.98 & 994.49 & 282.86 & 449.66 & 407.15 \\
\hline 0.009 & 933.74 & 941.31 & 983.13 & 280.86 & 445.94 & 404.11 \\
\hline 0.0095 & 922.65 & 930.82 & 971.97 & 278.91 & 442.29 & 401.13 \\
\hline 0.01 & 911.75 & 920.51 & 961.00 & 276.99 & 438.70 & 398.21 \\
\hline 0.0105 & 901.04 & 910.39 & 950.22 & 275.10 & 435.17 & 395.34 \\
\hline 0.011 & 890.51 & 900.44 & 939.63 & 273.25 & 431.71 & 392.52 \\
\hline 0.0115 & 880.17 & 890.67 & 929.22 & 271.44 & 428.31 & 389.76 \\
\hline 0.012 & 870.00 & 881.08 & 919.00 & 269.66 & 424.97 & 387.05 \\
\hline 0.0125 & 860.02 & 871.66 & 908.96 & 267.92 & 421.69 & 384.39 \\
\hline 0.013 & 850.22 & 862.41 & 899.1 & 266.21 & 418.48 & 381.78 \\
\hline 0.0135 & 840.60 & 853.33 & 889.43 & 264.53 & 415.32 & 379.22 \\
\hline 0.014 & 831.15 & 844.42 & 879.92 & 262.89 & 412.21 & 376.71 \\
\hline 0.0145 & 821.88 & 835.68 & 870.60 & 261.27 & 409.17 & 374.24 \\
\hline 0.015 & 812.77 & 827.09 & 861.44 & 259.69 & 406.17 & 371.83 \\
\hline 0.0155 & 803.84 & 818.67 & 852.46 & 258.13 & 403.24 & 369.45 \\
\hline
\end{tabular}

inflation has not been addressed in supply chain management applications. Given this, we explore the effect of inflation on supply chain decisions and performance. Moreover, the effect of inflation has been studied in financial applications and options are deemed to be effective to protect against the effect of inflation. However, the studies which incorporate option contracts and the effect of inflation are rare in supply chain management applications. Given this, we explore the impact of option contracts on supply chain decisions and performance under inflation scenarios. Furthermore, the supplier's optimal production quantity also needs coordinate in the presence of option contracts. Given this, we design the bilateral coordination mechanism from the perspective of both the supplier and the retailer. Our objective is to contribute to providing insights into the effect of inflation and option contracts on supply chain.

In this paper, we study the procurement, production, and coordination strategies with and without option contracts under inflation scenarios. We take wholesale price contracts model as the benchmark and give insights into the impact of option contracts on supply chain decisions and performance under inflation scenarios. By comparing results under three different contracts, we deduce that the retailer's total order quantity is higher with option contracts than without option contracts, while the retailer's firm order quantity is lower with option contracts than without option contracts. These conclusions provide guidance for the companies on how to make appropriate procurement decisions under inflation scenarios. We also deduce that the supplier's production decision is more complex with option contracts than without option contracts. These conclusions provide guidance for the companies on how to make appropriate production decisions under inflation scenarios. Moreover, we deduce that the introduction of option contracts can benefit both the supplier and the retailer under inflation scenarios. The retailer prefers adopting portfolio contracts and the supplier is only inclined to provide option contracts. These conclusions provide guidance for the companies on how to choose appropriate contracting arrangement under inflation scenarios. Furthermore, we deduce that option contracts are ultimately carried out by the supply chain under inflation scenarios. Thus, we design the bilateral coordination mechanism from the perspective of both the supplier and the retailer and deduce the coordination conditions with option contracts under inflation scenarios. These conclusions provide a good way on how to align the supply chain members' incentives to drive the optimal action under inflation scenarios. Our objective is to help the members better optimize their decisions and increase their revenues when they face inflationary pressure and option games.

There still exist some limitations in this paper. We only consider a one-period setting, and we plan to extend our research to a multiperiod setting. Besides, both the retailer and the supplier are supposed to be risk-neutral. In reality, the decision-making behaviors of most enterprises are consistent with loss-aversion [30]. In addition, we assume that the market structure is supplier Stackelberg in this paper, and we should consider other market power, such as retailer Stackelberg and vertical Nash $[40,41]$ in the future. Furthermore, option contracts are classified into three different categories. In this paper, we focus our discussion on call option contracts. Put or bidirectional option contracts [42] will be taken into consideration in the future.

\section{Notations}

$t$ : The length of production lead time, following probability density function (PDF) $g(\cdot)$ within the interval $(0, T)$

$d(t)$ : Deterministic part of the market demand, following an exponentially decreasing function of the production lead time due to the effect of inflation; that is, $d(t)=\lambda e^{-\alpha t}$, where $\lambda$ is the initial market scale and $\alpha(\alpha>0)$ is the demand contraction factor 
$\xi: \quad$ Stochastic part of the market demand, following probability density function (PDF) $f(\cdot)$ and strictly increasing cumulative distribution function (CDF) $F(\cdot)$ within the interval $(0,+\infty)$

$p(t)$ : Unit retail price of product, following an exponentially increasing function of the production lead time due to the effect of inflation; that is, $p(t)=p e^{\gamma t}$, where $p$ is the initial retail price and $\gamma(\gamma>0)$ is the price rising factor

$w$ : Unit wholesale price of product

$c_{o}$ : Unit purchase price of call option

$c_{e}$ : Unit exercise price of call option

$c$ : Unit production cost of product

$g_{r}:$ Retailer's unit shortage cost for unsatisfied demand

$g_{s}: \quad$ Supplier's unit penalty cost for each exercised option that cannot be immediately filled

$Q_{r i}:$ Retailer's firm order quantity $(i=0,1,2)$

$q_{r i}: \quad$ Retailer's options order quantity $(i=0,1,2)$

$Q_{i}: \quad$ Retailer's total order quantity $(i=0,1,2)$. Note that $Q_{i}=Q_{r i}+q_{r i}$

$Q_{s i}:$ Supplier's production quantity $(i=0,1,2)$.

\section{Conflict of Interests}

The authors declare that there is no conflict of interests regarding the publication of this paper.

\section{Acknowledgments}

This research is partially supported by the National Natural Science Foundation of China (nos. 71432003 and 71272128), Program for New Century Excellent Talents in University (no. NCET-12-0087), Specialized Research Fund for the Doctoral Program of Higher Education of China (no. 20130185110006), and Youth Foundation for Humanities and Social Sciences of Ministry of Education of China (no. 11YJC630022).

\section{References}

[1] Statistics, Global Inflation Rate from 2004 to 2014, 2015, http://www.statista.com/statistics/256598.

[2] Z. Bodie, "Inflation insurance," The Journal of Risk and Insurance, vol. 57, no. 4, pp. 634-645, 1990.

[3] Q. Wang and D.-B. Tsao, "Supply contract with bidirectional options: the buyer's perspective," International Journal of Production Economics, vol. 101, no. 1, pp. 30-52, 2006.

[4] Y. Zhao, L. Ma, G. Xie, and T. C. E. Cheng, "Coordination of supply chains with bidirectional option contracts," European Journal of Operational Research, vol. 229, no. 2, pp. 375-381, 2013.
[5] V. Nagali, J. Hwang, D. Sanghera et al., "Procurement risk management (PRM) at Hewlett-Packard company," Interfaces, vol. 38, no. 1, pp. 51-60, 2008.

[6] Z. J. Ren, M. A. Cohen, T. H. Ho, and C. Terwiesch, "Information sharing in a long-term supply chain relationship: the role of customer review strategy," Operations Research, vol. 58, no. 1, pp. 81-93, 2010.

[7] Ç. Haksöz and K. D. Şimşek, "Modeling breach of contract risk through bundled options," The Journal of Operational Risk, vol. 5, no. 3, pp. 3-20, 2010.

[8] J. J. Spengler, "Vertical integration and antitrust policy," The Journal of Political Economy, vol. 58, no. 4, pp. 347-352, 1950.

[9] G. J. Gutierrez and X. He, "Life-cycle channel coordination issues in launching an innovative durable product," Production and Operations Management, vol. 20, no. 2, pp. 268-279, 2011.

[10] J. K. Dey, S. K. Mondal, and M. Maiti, “Two storage inventory problem with dynamic demand and interval valued lead-time over finite time horizon under inflation and time-value of money," European Journal of Operational Research, vol. 185, no. 1, pp. 170-194, 2008.

[11] C. K. Jaggi and A. Khanna, "Retailer's ordering policy for deteriorating items with inflation-induced demand under trade credit policy," International Journal of Operational Research, vol. 6, no. 3, pp. 360-379, 2009.

[12] H.-L. Yang, J.-T. Teng, and M.-S. Chern, "An inventory model under inflation for deteriorating items with stock-dependent consumption rate and partial backlogging shortages," International Journal of Production Economics, vol. 123, no. 1, pp. 8-19, 2010.

[13] B. Sarkar, S. S. Sana, and K. Chaudhuri, "An imperfect production process for time varying demand with inflation and time value of money-an EMQ model," Expert Systems with Applications, vol. 38, no. 11, pp. 13543-13548, 2011.

[14] R. P. Tripathi, "Optimal pricing and ordering policy for inflation dependent demand rate under permissible delay in payments," International Journal of Business, Management and Social Sciences, vol. 2, no. 4, pp. 35-43, 2011.

[15] J. Taheri-Tolgari, A. Mirzazadeh, and F. Jolai, "An inventory model for imperfect items under inflationary conditions with considering inspection errors," Computers \& Mathematics with Applications, vol. 63, no. 6, pp. 1007-1019, 2012.

[16] A. Mirzazadeh, "Optimal inventory control problem with inflation-dependent demand rate under stochastic conditions," Research Journal of Applied Sciences, Engineering and Technology, vol. 4, no. 4, pp. 306-315, 2012.

[17] A. Guria, B. Das, S. Mondal, and M. Maiti, "Inventory policy for an item with inflation induced purchasing price, selling price and demand with immediate part payment," Applied Mathematical Modelling, vol. 37, no. 1-2, pp. 240-257, 2013.

[18] S. M. Mousavi, V. Hajipour, S. T. A. Niaki, and N. Alikar, "Optimizing multi-item multi-period inventory control system with discounted cash flow and inflation: two calibrated metaheuristic algorithms," Applied Mathematical Modelling, vol. 37, no. 4, pp. 2241-2256, 2013.

[19] B. H. Gilding, "Inflation and the optimal inventory replenishment schedule within a finite planning horizon," European Journal of Operational Research, vol. 234, no. 3, pp. 683-693, 2014.

[20] S. Pal, G. Mahapatra, and G. Samanta, "A production inventory model for deteriorating item with ramp type demand allowing inflation and shortages under fuzziness," Economic Modelling, vol. 46, pp. 334-345, 2015. 
[21] H. Li, P. Ritchken, and Y. Wang, "Option and forward contracting with asymmetric information: valuation issues in supply chains," European Journal of Operational Research, vol. 197, no. 1, pp. 134-148, 2009.

[22] Y. Zhao, S. Wang, T. C. E. Cheng, X. Yang, and Z. Huang, "Coordination of supply chains by option contracts: a cooperative game theory approach," European Journal of Operational Research, vol. 207, no. 2, pp. 668-675, 2010.

[23] H. Xu, "Managing production and procurement through option contracts in supply chains with random yield," International Journal of Production Economics, vol. 126, no. 2, pp. 306-313, 2010.

[24] Q. Fu, C.-Y. Lee, and C.-P. Teo, "Procurement management using option contracts: Random spot price and the portfolio effect," IIE Transactions, vol. 42, no. 11, pp. 793-811, 2010.

[25] Y. Xia, K. Ramachandran, and H. Gurnani, "Sharing demand and supply risk in a supply chain," IIE Transactions, vol. 43, no. 6, pp. 451-469, 2011.

[26] X. Chen and Z.-J. Shen, "An analysis of a supply chain with options contracts and service requirements," IIE Transactions, vol. 44, no. 10, pp. 805-819, 2012.

[27] L. Liang, X. Wang, and J. Gao, "An option contract pricing model of relief material supply chain," Omega, vol. 40, no. 5, pp. 594-600, 2012.

[28] C.-Y. Lee, X. Li, and Y. Xie, "Procurement risk management using capacitated option contracts with fixed ordering costs," IIE Transactions, vol. 45, no. 8, pp. 845-864, 2013.

[29] C. Liu, Z. Jiang, L. Liu, and N. Geng, "Solutions for flexible container leasing contracts with options under capacity and order constraints," International Journal of Production Economics, vol. 141, no. 1, pp. 403-413, 2013.

[30] X. Chen, G. Hao, and L. Li, "Channel coordination with a lossaverse retailer and option contracts," International Journal of Production Economics, vol. 150, pp. 52-57, 2014.

[31] F. Hu, C.-C. Lim, and Z. Lu, "Optimal production and procurement decisions in a supply chain with an option contract and partial backordering under uncertainties," Applied Mathematics and Computation, vol. 232, pp. 1225-1234, 2014.

[32] C. T. Linh and Y. Hong, "Channel coordination through a revenue sharing contract in a two-period newsboy problem," European Journal of Operational Research, vol. 198, no. 3, pp. 822-829, 2009.

[33] T. Xiao, J. Jin, G. Chen, J. Shi, and M. Xie, "Ordering, wholesale pricing and lead-time decisions in a three-stage supply chain under demand uncertainty," Computers \& Industrial Engineering, vol. 59, no. 4, pp. 840-852, 2010.

[34] T. Xiao, K. Shi, and D. Yang, "Coordination of a supply chain with consumer return under demand uncertainty," International Journal of Production Economics, vol. 124, no. 1, pp. 171180, 2010.

[35] C.-H. Chiu, T.-M. Choi, and C. S. Tang, "Price, rebate, and returns supply contracts for coordinating supply chains with price-dependent demands," Production and Operations Management, vol. 20, no. 1, pp. 81-91, 2011.

[36] G. P. Cachon, "Supply chain coordination with contracts," in Handbooks in Operations Research and Management Science, vol. 11, chapter 6, pp. 227-339, University of Pennsylvania, Philadelphia, Pa, USA, 2003.

[37] A. V. Iyer and M. E. Bergen, "Quick response in manufacturerretailer channels," Management Science, vol. 43, no. 4, pp. 559570, 1997.
[38] J. G. Shanthikumar and U. Sumita, "Approximations for the time spent in a dynamic job shop with applications to due-date assignment," International Journal of Production Research, vol. 26, no. 8, pp. 1329-1352, 1988.

[39] U. S. Karmarkar, "Manufacturing lead times, order release and capacity loading," in Handbooks in Operations Research and Management Science, vol. 4, pp. 287-329, Elsevier, 1993.

[40] X. Chen, X. Wang, and X. Jiang, "The impact of power structure on the retail service supply chain with an $\mathrm{O} 2 \mathrm{O}$ mixed channel," Journal of the Operational Research Society, 2015.

[41] X. Chen and X. Wang, "Free or bundled: channel selection decisions under different power structures," Omega, vol. 53, pp. 11-20, 2015.

[42] N. Wan and X. Chen, "Bilateral coordination strategy of supply chain with bidirectional option contracts under inflation," Mathematical Problems in Engineering, vol. 2015, Article ID 369132, 16 pages, 2015. 


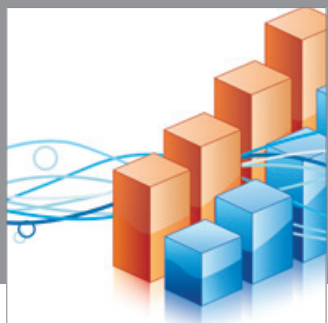

Advances in

Operations Research

mansans

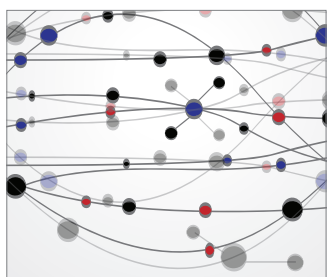

The Scientific World Journal
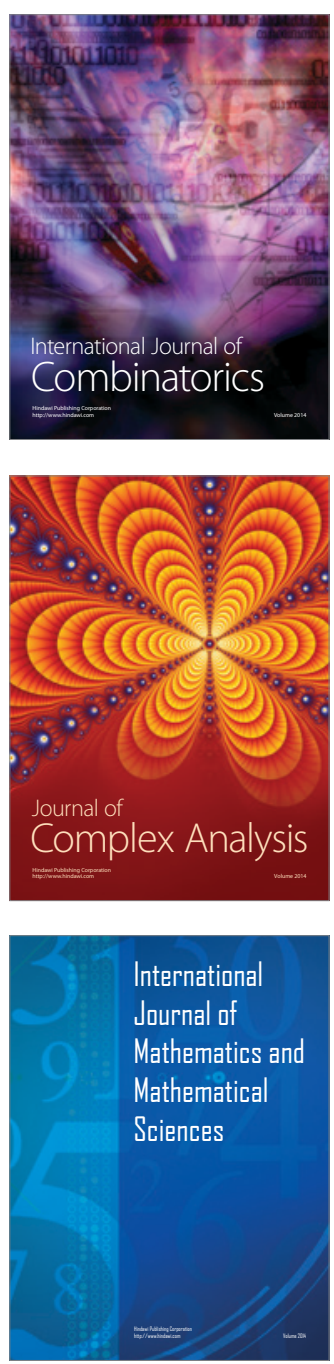
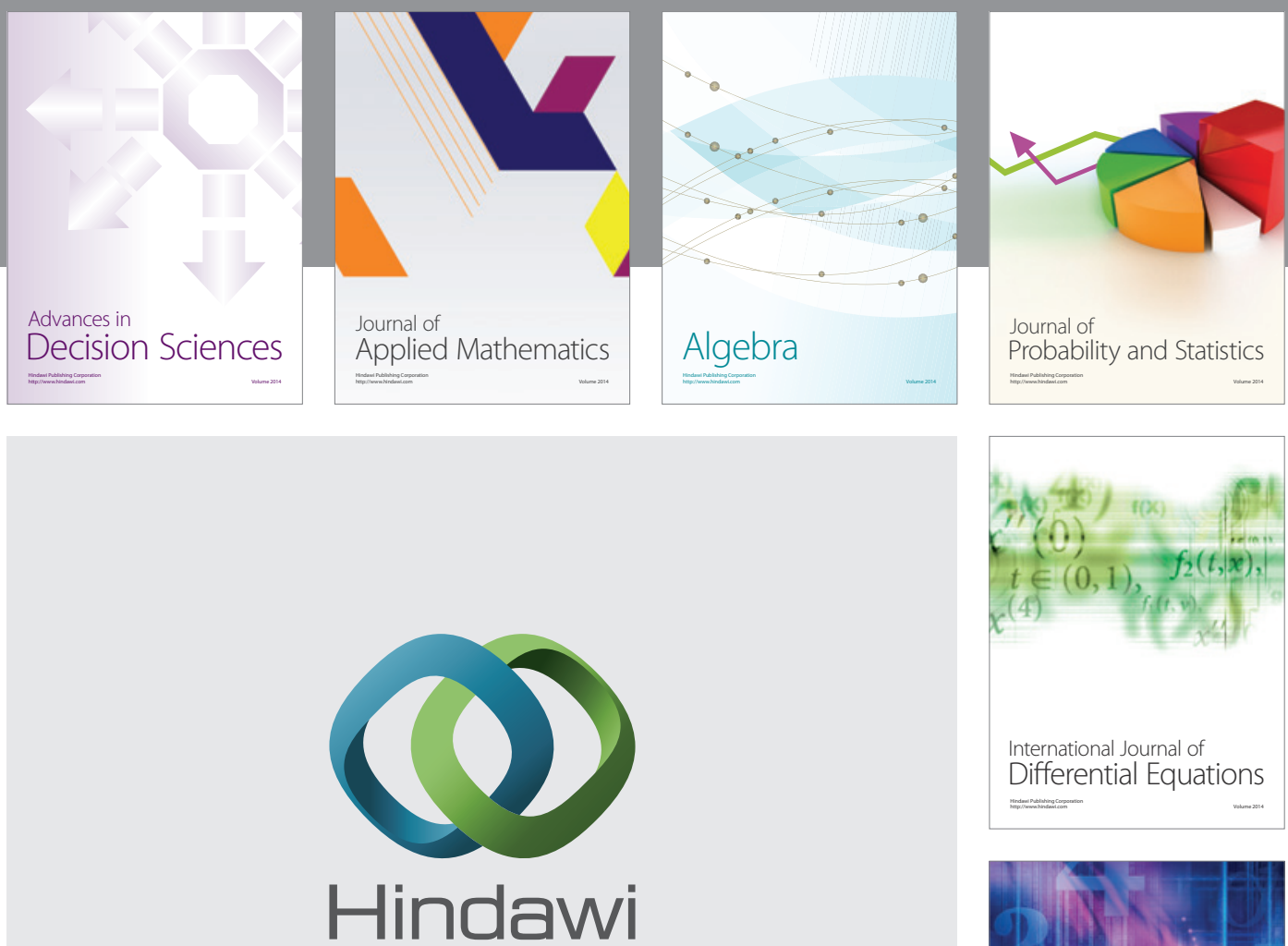

Submit your manuscripts at http://www.hindawi.com
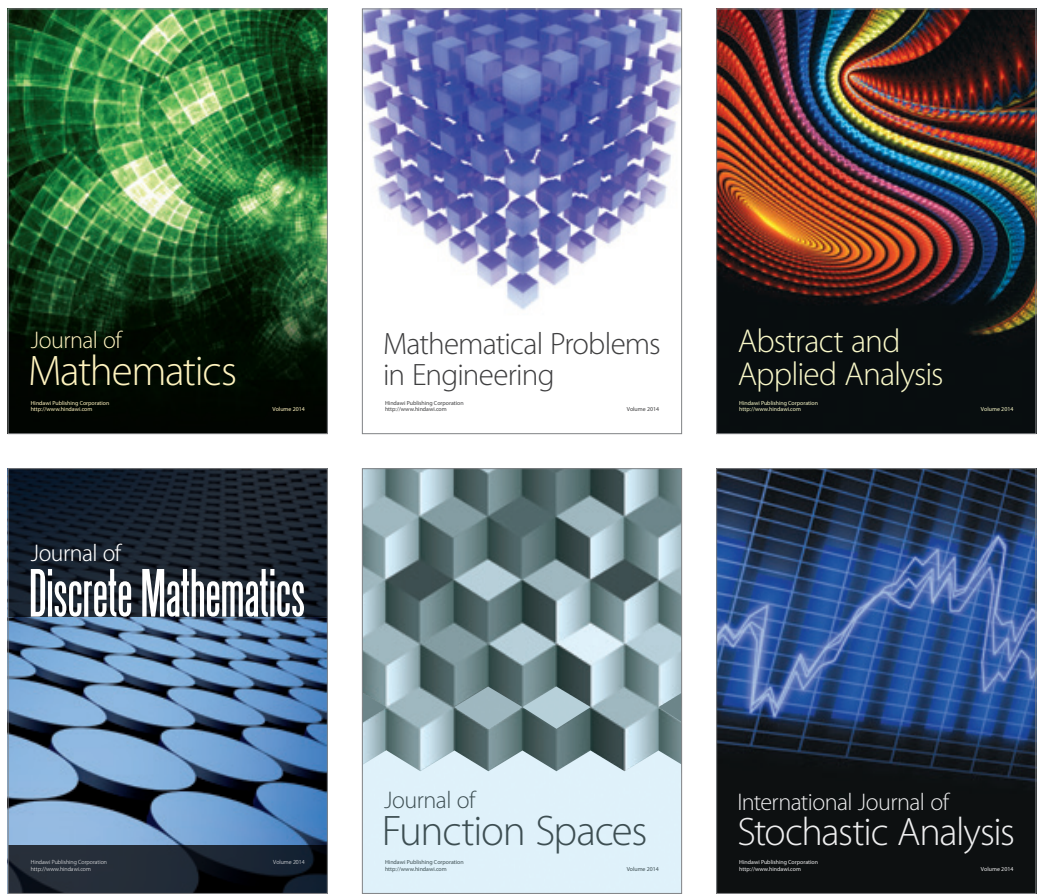

Journal of

Function Spaces

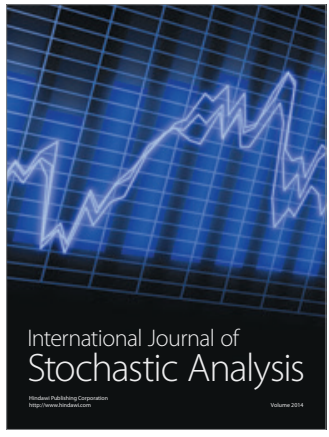

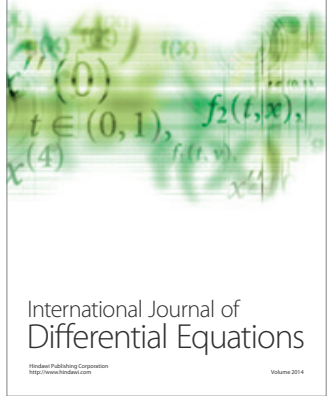
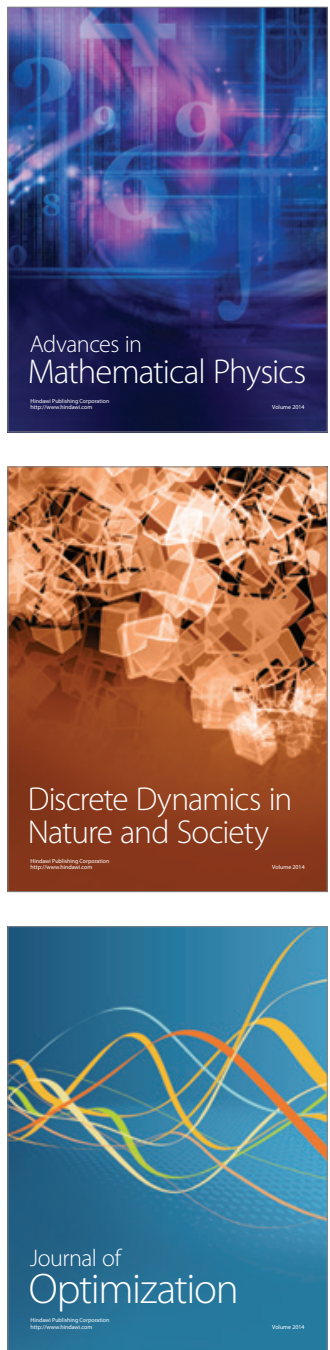